\title{
OVERVIEW OF THE HI-SCALE FIELD CAMPAIGN A New Perspective on Shallow Convective Clouds
}

\author{
Jerome D. Fast, Larry K. Berg, Lizbeth AleXander, David Bell, Emma D'Ambro, John Hubbe, Chongai Kuang, \\ Jiumeng Liu, Chuck Long, Alyssa Matthews, Fan Mei, Rob Newsom, Mikhall Pekour, Tamara Pinterich, \\ Beat Schmid, Siegfried Schobesberger, John Shilling, James N. Smith, Stephen Springston, Kaitlyn Suski, \\ Joel A. Thornton, Jason Tomlinson, Jian Wang, Heng Xiao, and Alla Zelenyuk
}

The HI-SCALE campaign provides new measurements to better understand and model shallow convective clouds and their coupling to land-atmosphere interactions, boundary layer turbulence, and the aerosol life cycle.

$\int$ hallow convective clouds are common, occurring over many areas of the world, and are an important component in the atmospheric radiation budget. Over the southern Great Plains, shallow convective clouds frequently occur during the summertime growing season when intense turbulence induced by surface radiation couples the land surface to clouds. Shallow cumuli at the U.S. Department of Energy's Atmospheric Radiation Measurement (ARM) Climate Research Facility's Southern Great
Plains (SGP) site in Oklahoma (Sisterson et al. 2016) have an average surface shortwave radiative forcing of $-45.5 \mathrm{~W} \mathrm{~m}^{-2}$ (Berg et al. 2011b) and mean spatial scale of $\sim 1.0 \mathrm{~km}$ (Berg and Kassianov 2008), which means they occur at the subgrid scale for all current climate, operational forecast, and cloud-system-resolving models and must be represented by parameterizations (e.g., Randall 2013).

The southern Great Plains is also known as a "hot spot" for land-atmosphere interactions that
Affiliations: Fast, Berg, Alexander, Hubbe, Matthews, Mei, Newsom, Pekour, Schmid, Shilling, Suski, Tomlinson, Xiao, and ZelenYuk-Pacific Northwest National Laboratory, Richland, Washington; BeLL- Pacific Northwest National Laboratory, Richland, Washington, and Laboratory of Atmospheric Chemistry, Paul Scherrer Institute, Villigen, Switzerland; D'AMBRO AND THORNTON-University of Washington, Seattle, Washington; KuANG, PINTERICH, AND SPRINGston-Brookhaven National Laboratory, Upton, New York; LıU—Pacific Northwest National Laboratory, Richland, Washington, and Harbin Institute of Technology, Harbin, China; LONG—NOAA/Earth System Research Laboratory, Boulder, Colorado; SCHOBESBERGER-University of Washington, Seattle, Washington, and University of Eastern Finland, Kuopio, Finland; SMITH—University of California, Irvine,
Irvine, California; WANG-Brookhaven National Laboratory, Upton, New York, and Washington University in St. Louis,

St. Louis, Missouri CORRESPONDING AUTHOR: Jerome D. Fast, jerome.fast@pnnl.gov

The abstract for this article can be found in this issue, following the table of contents. DOI:10.II75/BAMS-D-18-0030.I

A supplement to this article is available online (I0.II75/BAMS-D-18-0030.2)

In final form 13 November 2018 (0)2019 American Meteorological Society

For information regarding reuse of this content and general copyright information, consult the AMS Copyright Policy. 
influences the life cycle of shallow convection. Several climate modeling studies have identified regions, including the southern Great Plains, where coupling between surface processes and precipitation is the strongest (e.g., Koster et al. 2004, 2006; Dirmeyer et al. 2006). Other studies that rely on measurements suggest that the land-atmosphere coupling strength from climate models may be too large (Phillips et al. 2017; Tuttle and Salvucci 2016). But the spatial heterogeneity of soil moisture and type, vegetation distribution and phenology, and fluxes within model grid cells and their effects on boundary layer mixing and clouds are often neglected or treated in a simplistic way (e.g., Essery et al. 2003; Berg et al. 2015; Rieck et al. 2014).

In addition to synoptic and mesoscale meteorological conditions, aerosol-radiation-cloud interactions (e.g., Boucher et al. 2013) can influence cloud formation, microphysics, albedo, and precipitation. While the processes controlling cloud-aerosol interactions for marine stratiform are well known (e.g., Twohy et al. 2005; Wood 2012) since their spatiotemporal scales are ideal for aircraft sampling, there are larger uncertainties associated with cloud-aerosol interactions in convective clouds (Fan et al. 2016) that are more difficult to sample. Some studies (e.g., Berg et al. 2011a; Lu et al. 2008) show that aerosols even affect the properties of shallow cumulus; therefore, it is important to characterize how heterogeneity in aerosol properties alters cloud condensation nuclei (CCN) distributions.

Uncertainties in shallow cloud parameterization predictions arise from many sources, including insufficient coincident data that couple cloud macrophysical and microphysical properties to inhomogeneity in the surface-layer, boundary layer, and aerosol properties. Coincident data are a key factor needed to achieve a more complete understanding of the life cycle of shallow convective clouds, including the transition of shallow to deep convection, and to develop improved model parameterizations of convection. Long-term and short-term (Weckwerth et al. 2004; Berg et al. 2009; Vogelmann et al. 2012; Jensen et al. 2015) measurements collected near the ARM SGP site since 1992 have already provided valuable information needed to improve the understanding of specific processes associated with many cloud types. Some of the remaining scientific issues associated with shallow convective clouds include 1) the effects of heterogeneous land-use, vegetation, and soil moisture conditions (natural or human activities) on boundary layer mixing and consequently cloud formation, initiation of precipitation (especially drizzle), and transition from shallow to deep convection; 2 ) the role of cloud population (size, organization) and entrainment on precipitation onset and cloud lifetime under different aerosol environments; 3) the sensitivity of $\mathrm{CCN}$ number concentrations to the mixing state of secondary organic aerosol (SOA) resulting from biomass burning and/or biogenic-anthropogenic interactions; and 4) the impact of new particle formation (NPF) on the growth of aerosol populations and consequently $\mathrm{CCN}$.

To address these knowledge gaps, the Holistic Interactions of Shallow Clouds, Aerosols and Land

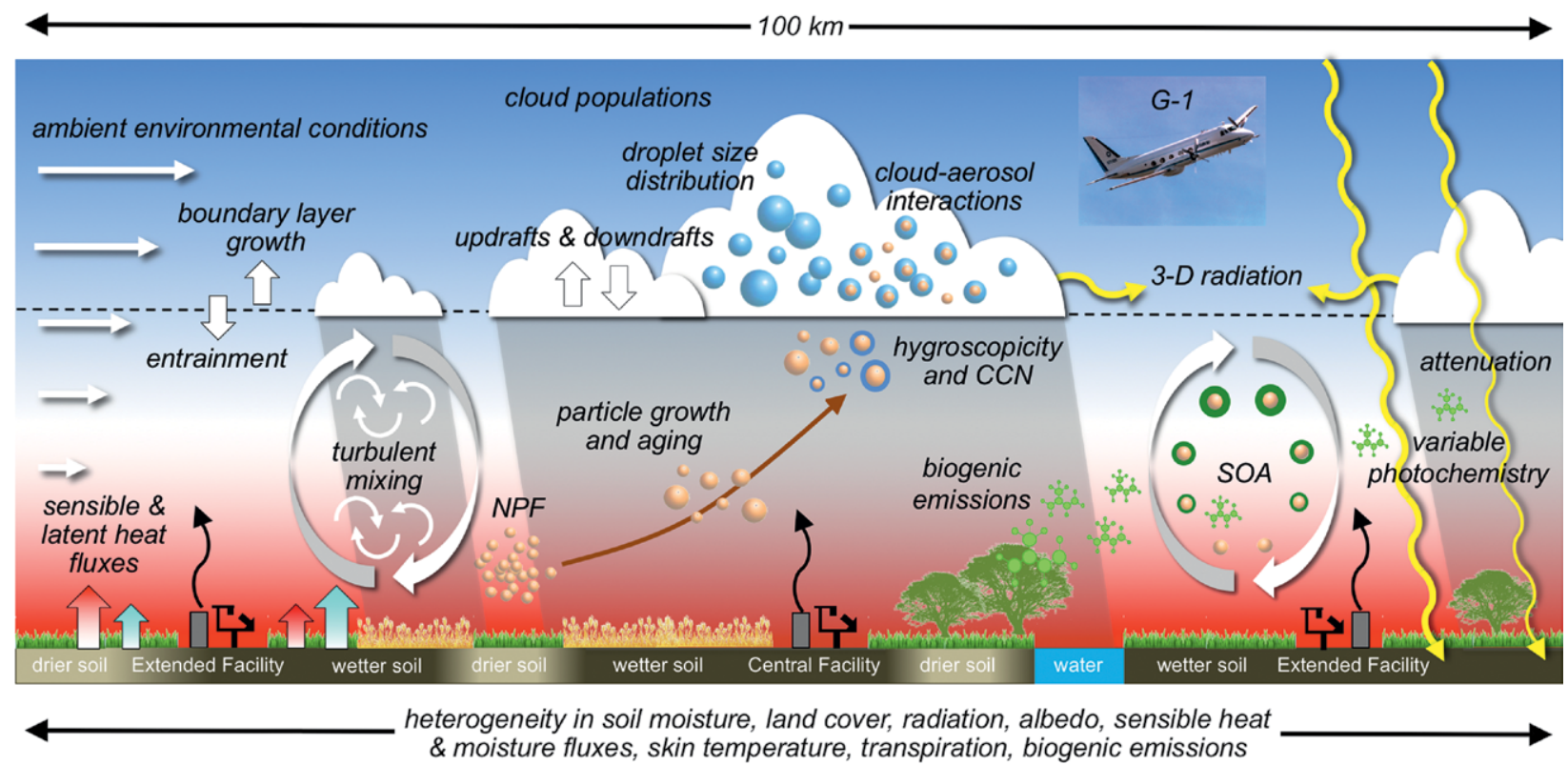

FIG. I. Schematic diagram depicting the primary physical processes of interest to the HI-SCALE campaign that influence the evolution of shallow convective clouds. 
Ecosystems (HI-SCALE) campaign was recently conducted near the ARM SGP site.

EXPERIMENTAL GOALS. The first objective of the HI-SCALE campaign is to obtain a holistic understanding of the life cycle of shallow clouds by coupling cloud macrophysical and microphysical properties to land surface properties, ecosystems, and aerosols. As illustrated in Fig. 1, this includes quantifying the influence of heterogeneities in land use, vegetation, soil moisture, convective eddies, and aerosol properties on the evolution of shallow clouds as well as the feedbacks of cloud radiative effects on the surface heat, moisture, and momentum fluxes and on aerosol photochemical processes via changes in the downwelling radiation reaching the surface. The second objective of the campaign is to provide critical in situ measurements of the boundary layer, cloud microphysics and dynamics, and aerosol properties, which are needed to evaluate high-resolution simulations and improve the representation of shallow clouds in models.

To achieve these objectives, coincident measurements of meteorological, cloud, and aerosol properties were collected by the ARM Aerial Facility's Gulfstream 1 (G-1) aircraft platform (Schmid et al. 2014) over the SGP site. Additional aerosol instruments were also deployed on the ground to obtain similar measurements as the G-1 aircraft. The campaign consisted of two 4-week intensive observational periods (IOPs), one between 24 April and 21 May (denoted "spring" IOP) and one between 28 August and 24 September (denoted "summer" IOP) to take advantage of different stages and distribution of the "greenness" for cultivated crops, pastures, and herbaceous and forest vegetation types as well as variations in soil moisture content.

EXPERIMENTAL APPROACH. During 2016, the SGP site was reconfigured into a "megasite" (ARM 2014) that provided a spatially denser array of surface in situ measurements as well as new vertically pointing instruments at boundary locations [e.g., Doppler lidars and Atmospheric Emitted Radiance Interferometers (AERI)] and scanning remote sensing (e.g., cloud radars) to obtain additional information on the meteorological state and cloud properties. The current sampling sites are shown as red symbols in Fig. 2. ARM also routinely measures fluxes of

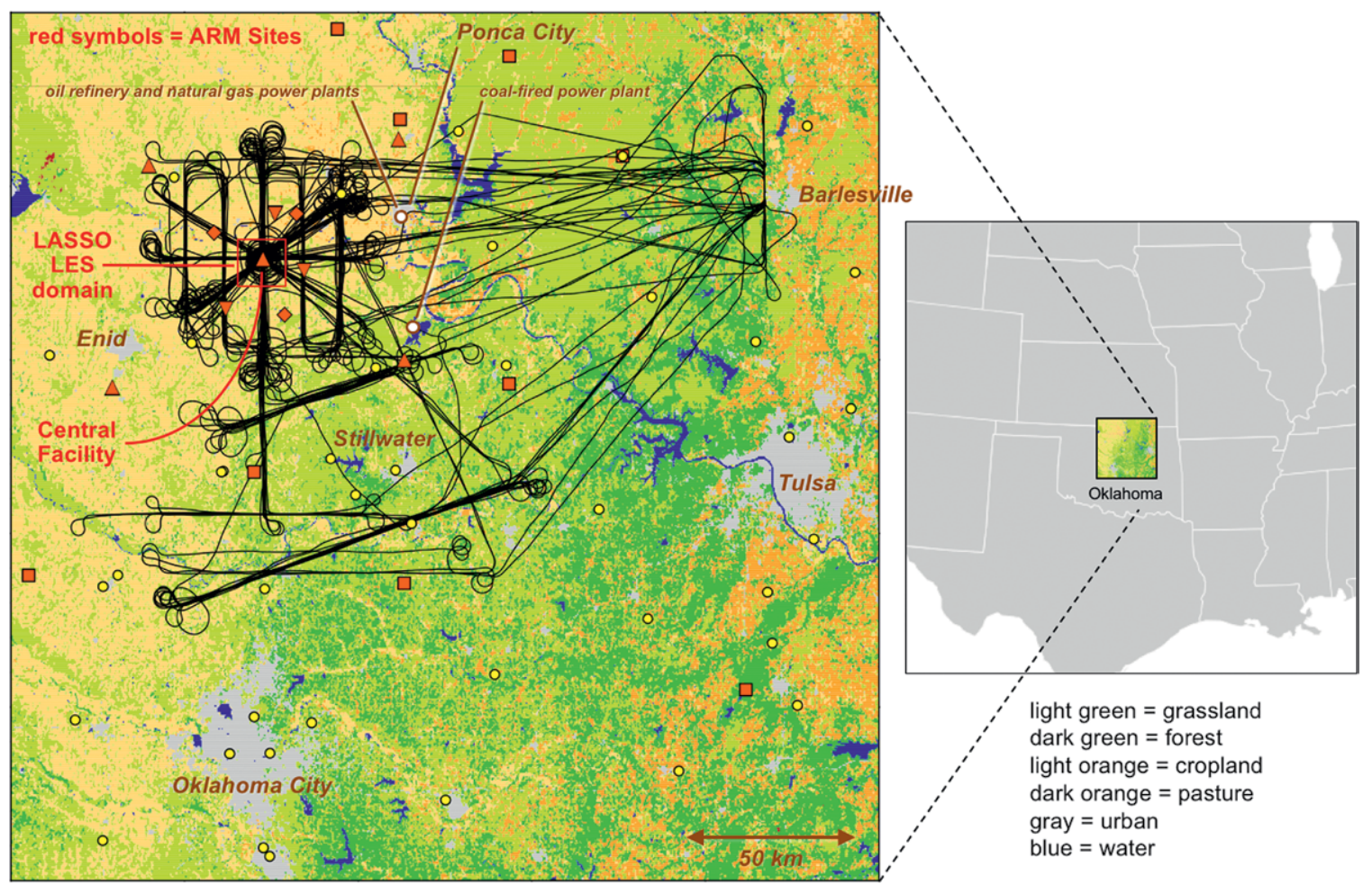

FIG. 2. Locations of the ARM SGP measurement sites (red symbols) along with the flight paths of the G-I aircraft during the spring IOP (black lines) and Oklahoma Mesonet sites (yellow circles). Red squares denote surface measurements only, while the red triangles, upside-down triangles, and diamonds denote various vertical remote and in situ samplings along with surface measurements. Color shading denotes lumped National Land Cover Database (NLCD; Homer et al. 20I5) land-cover classification. 
heat, moisture, and momentum; soil moisture and temperature; radiation; and many meteorological parameters at 17 sites over north-central Oklahoma. Radiosondes are launched from the Central Facility four times per day. The site also has instrumentation to measure aerosol optical properties (e.g., scattering and absorption), hygroscopic growth, aerosol size distribution, bulk nonrefractory aerosol composition, and $\mathrm{CCN}$ from the Central Facility. A detailed list of the instrumentation used can be found in Sisterton et al. (2016). The Oklahoma Mesonet (McPherson et al. 2007) collects measurements of surface meteorology, soil moisture, and soil temperature at 140 sites across the state that provide a regional-scale context of the SGP megasite measurements.

Measurements from the reconfigured site may still not be sufficient to fully characterize the true spatial variability of the local meteorology and cloud populations; therefore, the G-1 aircraft was deployed to supplement the SGP megasite data collection effort by obtaining additional measurements that characterize spatial and temporal variability. In addition, in situ aircraft sampling can be used to verify and supplement cloud retrievals from remote sensing instrumentation.

The horizontal flight patterns for the spring IOP depicted in Fig. 2 show that most of the sampling was conducted within $100 \mathrm{~km}$ of the Central Facility. West-to-east transects south of the megasite were also performed to sample air upwind of the SGP site and identify gradients associated with land-use variations. The flight patterns during the summer IOP were similar to those for the spring IOP. These flights often sampled along constant-altitude transects near the middle of the boundary layer, just below cloud base, within the shallow clouds, and just above the shallow clouds. Profiles up to $3.5 \mathrm{~km}$ above mean sea level (MSL) were also performed using either spirals or ascents-descents along straight transects.

Additional details of the experimental approach and weather conditions can be found in the online supplemental information (SI; https://doi.org//0.I I75 /BAMS-D-18-0030.2).

HI-SCALE instrumentation. The instruments deployed on the G-1 aircraft, listed in Table S1 in the online supplement, collected a wide range of meteorological, radiation, cloud, trace-gas, and aerosol measurements during the campaign. The Aircraft-Integrated Meteorological Measurement System (AIMMS-20) provided data, including the three-dimensional winds, at $20 \mathrm{~Hz}$. Almost all the other instruments sampled at a rate of $1 \mathrm{~Hz}$. Several instruments were deployed to have redundancy and as a means of understanding measurement uncertainty. Complementary measurements were made primarily for the droplet and aerosol size distribution, although they used different, yet overlapping, size ranges and bin size.

Instruments that sample trace gas concentrations of $\mathrm{CO}, \mathrm{O}_{3}, \mathrm{SO}_{2}$, and $\mathrm{NO}_{x}$ were deployed to identify air masses influenced by anthropogenic emission sources. A high-resolution time-of-flight chemical ionization mass spectrometer employing iodide adduct ionization (HR-ToF-CIMS; Lee et al. 2016) was also included to obtain trace gas concentrations of several biogenic and anthropogenic volatile organic compounds (VOCs). Two instruments were used to measure aerosol composition: a highresolution time-of-flight Aerosol Mass Spectrometer (HR-ToF-AMS; Canagaratna et al. 2007) and a single-particle mass spectrometer called miniSPLAT (Zelenyuk et al. 2015). The HR-ToF-AMS measures the bulk nonrefractory aerosol composition (sulfate, nitrate, ammonium, organic matter, chloride), while miniSPLAT measures the size (vacuum aerodynamic diameter $d_{\mathrm{va}}$ ), nonrefractory composition, and refractory composition (e.g., black carbon, sodium chloride, mineral dust) of several hundreds of individual particles per minute to obtain information on complex aerosol populations. Cloud condensation nuclei $(\mathrm{CCN})$ concentrations were obtained at two supersaturations $(0.24 \%$ and $0.46 \%)$.

Two aerosol-sampling inlets were used on the G-1. An isokinetic inlet permits sampling of interstitial aerosols with aerodynamic diameters less than $5 \mu \mathrm{m}$. A counterflow virtual impactor (CVI) inlet (Noone et al. 1993) imposes a counterflow airstream to selectively remove nonactivated particles so that small particles and droplets (diameter less than $\sim 13 \mu \mathrm{m}$ ) did not pass through the inlet. In this way, only cloud droplets and large aerosol particles pass through the inlet. The Fast Integrated Mobility Spectrometer (FIMS; Wang et al. 2017), HR-ToF-AMS, and miniSPLAT instruments could be switched between the isokinetic and CVI inlets, making it possible to compare the properties of cloud droplet residuals, interstitial aerosol at cloud altitude, and interstitial aerosol below the cloud (Zelenyuk et al. 2010).

As described in the SI (see Table S2), instruments similar to those on the G-1 aircraft were deployed at the Central Facility to obtain more detailed aerosol precursor, size distribution, and composition measurements than were available from SGP instrumentation.

The routine ARM measurements provide a valuable resource to cross validate the HI-SCALE data. 
For example, we found good agreement between the G-1 and radiosonde profiles of temperature, humidity, and winds when the aircraft flew close to the Central Facility around 1800 UTC (not shown). When the aircraft flew within the boundary layer and close to the Central Facility, its measurements can also be compared with the ground measurements to assess whether measured aerosol properties and CCN are consistent and well mixed within the convective boundary layer (not shown).

Routine high-resolution modeling. In 2015, the ARM Climate Research Facility initiated the development of a new high-resolution modeling activity to complement the extensive suite of measurements collected at the SGP megasite. The purpose of this activity, called the Large-Eddy Simulation (LES) ARM Symbiotic Simulation and Observation (LASSO) workflow, is to provide $4 \mathrm{D}$ representations of shallow convection (Gustafson et al. 2017b). Two models used are the Weather Research and Forecasting (WRF; Skamarock et al. 2008) Model and the System for Atmospheric Modeling (SAM; Khairoutdinov and Randall 2003). The model domain shown in Fig. 2 is $14.4 \mathrm{~km}$ wide and uses a $100-\mathrm{m}$ horizontal grid spacing. A total of 736 simulations from 20 cases for the summers of 2015 and 2016 (Gustafson et al. 2016, 2017a) are available from the ARM archive. Features of LASSO include

- an ensemble of large-scale forcing data for each simulated shallow convection day,

- an ensemble of LES results for each simulated day based on different large-scale forcings, and

- concurrent observations, skill scores, diagnostics, and quick-look plots bundled with each simulation.

The combination of observations with LES output in the LASSO data bundles and the growing number of simulation days in the library enables a more robust analysis of shallow cloud characteristics and model performance beyond the typical single-case approach commonly used for LES studies.

WEATHER CONDITIONS. Table S3 lists the times of the G-1 flights along with a brief description of the overall cloud conditions on each day. The G-1 aircraft flights during HI-SCALE were not limited to days with fair-weather cumulus and included other days with clear skies, cumulus transitioning to deeper convection, or more complex cloud populations, which are still useful in addressing a subset of science questions related to land surface properties, ecosystems, aerosols, and their interactions with clouds. Severe weather associated with both isolated and organized deep convection occurred during both IOPs. While the objectives of HI-SCALE did not specifically include deep convection, aircraft sampling on some days was done either prior to or shortly after thunderstorms.

Berg and Kassianov (2008) and Zhang and Klein (2013) describe similar methodologies of using ARM SGP measurements to determine days with single layers of shallow cumulus, ruling out days with more complicated cloud populations. For example, Zhang and Klein (2013) identified 119 days of shallow cumulus between May and August for a 13-yr period. Using a similar methodology, eight fair weather cumulus days occurred during both HI-SCALE IOPs over the SGP site (27 April; 8, 11, and 18 May; and 4, 6, 17 , and 20 September), which is somewhat above the climatological average. We note there were many days in which shallow cumulus formed in the presence of other clouds at higher altitudes (Table S3).

PRELIMINARY FINDINGS. Cloud characteristics. We focus here on measurements made on 30 August, when some shallow cumulus transitioned to cumulus congestus, showing in Fig. 3 how the observed cloud properties compared with those simulated by LES when using LASSO's current metrics. Figure 3a shows the observed lifting condensation level and clouds from the ARM's Active Remote Sensing of Clouds (ARSCL; Clothiaux et al. 2000) product that combines data from several remote sensors to determine a 10-min-averaged cloud mask. The temporal evolution of cloud depth from LASSO is qualitatively similar to ARSCL; however, simulated cumulus formed somewhere in the domain at 1000 central standard time (CST) and persisted beyond $1600 \mathrm{CST}$, when there were no observed clouds directly over the Central Facility. While this LASSO ensemble member did not produce the observed deep convection between 1900 and 2100 UTC, other ensemble members did. As shown in Fig. 3b, the observed liquid water path (LWP) obtained from a combination of ARM's AERI and Microwave Radiometer (MWR) reached a maximum value of $\sim 91 \mathrm{~g} \mathrm{~m}^{-2}$ at 1400 LST. However, the simulated domain-average LWP from LASSO is $2-3$ times larger than observed prior to 1400 LST. It is important to note that some of the differences between the observed and simulated quantities in Figs. $3 a$ and $3 b$ are due to metrics that compare narrow-field-of-view vertically pointing measurements with spatially varying quantities 
(a) Cloud Mask as a Function of Height

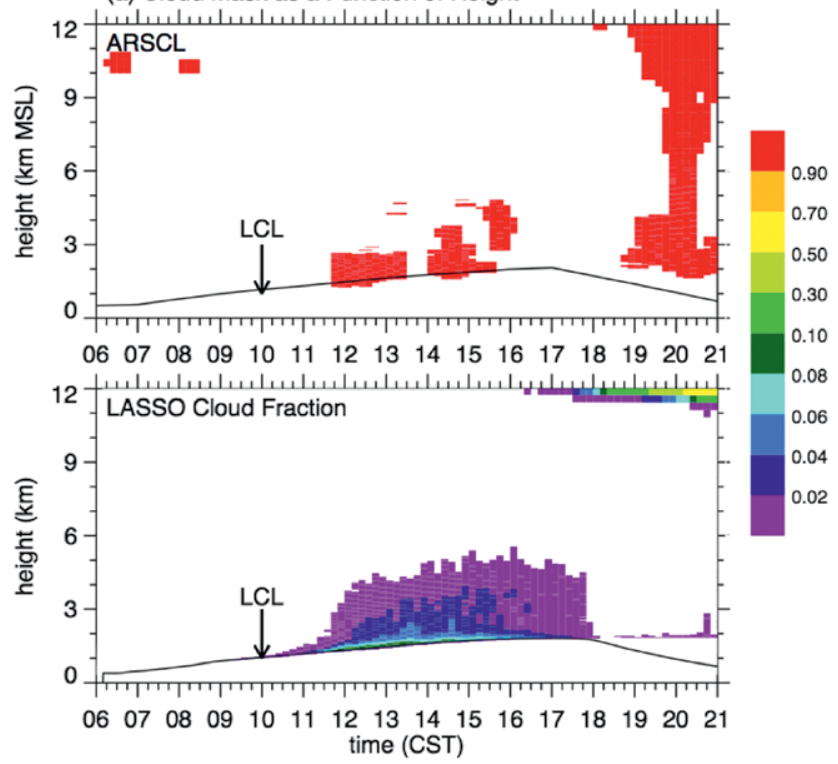

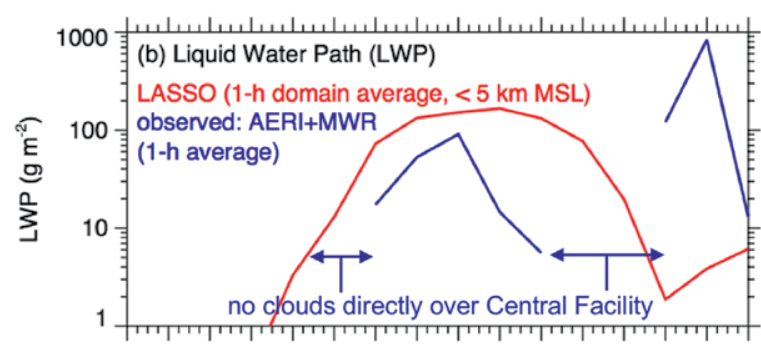

$\begin{array}{llllllllllllllll}06 & 07 & 08 & 09 & 10 & 11 & 12 & 13 & 14 & 15 & 16 & 17 & 18 & 19 & 20 & 21\end{array}$

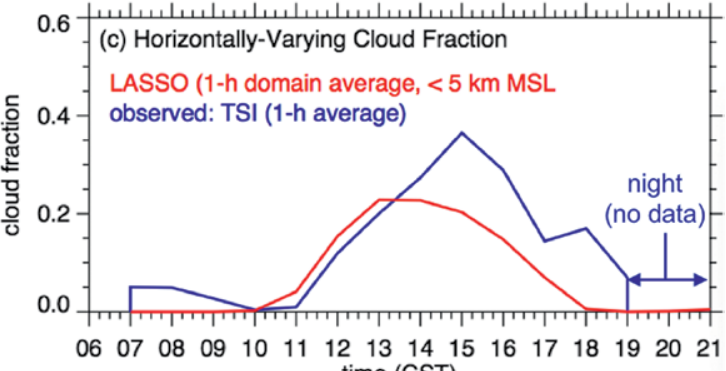
time (CST)

FIG. 3. Cloud properties simulated by LASSO on 30 Aug 2016 compared with ARM routine measurements including (a) cloud mask as a function of height and lifting condensation level (LCL), (b) LWP, and (c) horizontally varying cloud fraction. See text for definitions of ARM instruments and products.

from LASSO. The narrow field of view leads to no cloud properties being sampled for periods of time during partly cloudy conditions. A more consistent evaluation of simulated clouds is shown in Fig. 3c, which uses the cloud fraction derived from a totalsky imager (TSI). The TSI horizontally varying cloud fraction is representative of an area with a radius of about $5-10 \mathrm{~km}$ around the Central Facility, depending on cloud-base height. In this case, the observed and simulated temporal variations and magnitudes of the cloud fraction are very similar between 1100 and 1400 CST, but the simulated cloud fraction is too small the rest of the afternoon.

The LES results shown in Fig. 3 were one of the "best" of 21 WRF ensemble members, based on the standard LASSO metrics (Gustafson et al. 2017a). We now show other in situ cloud properties obtained from the G-1 in Fig. 4 to evaluate the LES predictions. Figures $4 \mathrm{a}$ and $4 \mathrm{~b}$ show the frequency distribution of vertical velocity measured inside the clouds during the morning and afternoon flights, respectively. While the vertical velocity magnitude from LASSO grows during the day, consistent with measurements, the distribution is too narrow. LASSO produced too many occurrences of near-zero vertical velocities and failed to produce the number of instances of strong updrafts and downdrafts. The WRF Model in LASSO uses the two-moment Morrison et al. (2009) parameterization for cloud microphysics that does not explicitly predict the cloud droplet distribution.
Instead, the cloud droplet size can be inferred from the parameterization's relationships. A comparison of observed and simulated concentrations as a function of droplet diameter in Figs. $4 \mathrm{c}$ and $4 \mathrm{~d}$ shows that the simulated peak droplet size occurs for somewhat smaller droplet diameters than was observed and that the median droplet concentration was much larger than observed. Nor does the model represent that bimodal distribution with an observed secondary peak around $17 \mu \mathrm{m}$. The observed bimodal distribution is likely the result of the G-1 flying at somewhat different altitudes above cloud base, with larger droplets likely occurring more frequently in the upper portions of clouds. Modeling studies have also shown that cumulus convection rising through air with previously evaporated cells also tends to have a bimodal spectra (Shaw et al. 1998).

Since the simulated droplet number is too high, it is not surprising that the simulated liquid water content is also larger than observed, as shown in Fig. 4e. These errors ultimately affect cloud optical depth estimates and the attenuation of radiation reaching the surface. In addition, the overall horizontal size of the simulated shallow cloud population depicted in Fig. $4 \mathrm{f}$ is somewhat smaller than estimates from the G-1 measurements that have median values of 440 and $640 \mathrm{~m}$ during the morning and afternoon flights, respectively. The observed cloud sizes tend to grow from the morning to the afternoon, consistent with satellite images. In contrast, the median size of 
a) w Distribution for Morning G-1 Flight

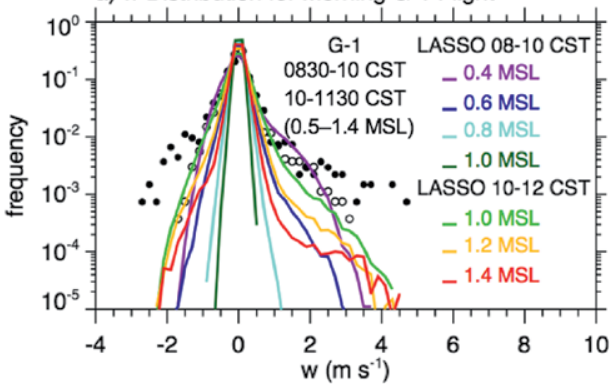

b) w Distribution for Afternoon G-1 Flight

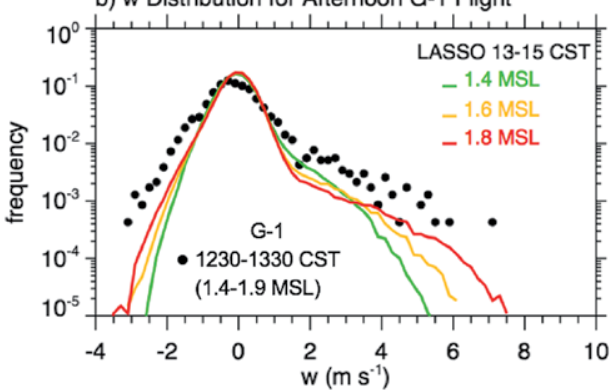

c) Droplet Distribution for Morning G-1 Flight

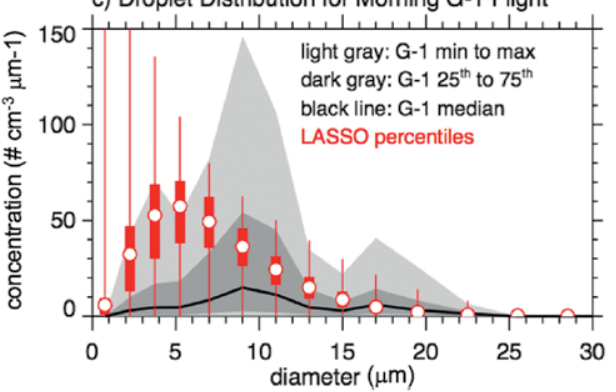

d) Droplet Distribution for Afternoon G-1 Flight

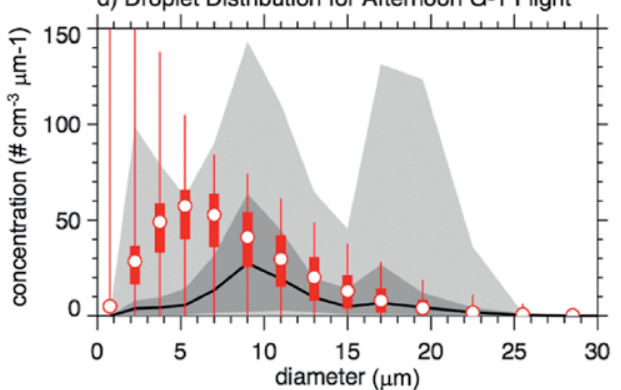

e) Liquid Water Content

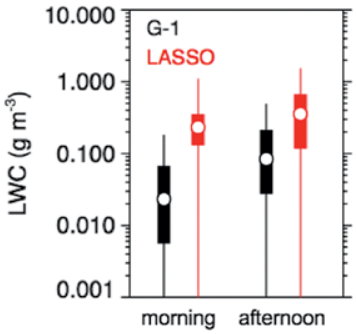

f) Cloud Size Distribution

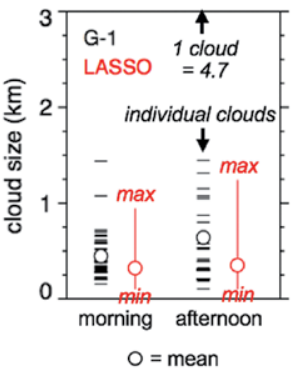

Fig. 4. Cloud properties simulated by LASSO on 30 Aug 2016 compared with HI-SCALE G-I aircraft measurements including vertical velocity distribution for the (a) morning and (b) afternoon G-I flights, cloud droplet distributions for the (c) morning and (d) afternoon flights, (e) LWC, and (f) cloud size distribution. Colored lines in (a) and (b) are LASSO results at various heights within the range of $G-I$ sampling altitudes. Percentiles in (c)-(e) are the median (open circle), 25th-75th percentiles (box), and minimum to maximum values (lines).
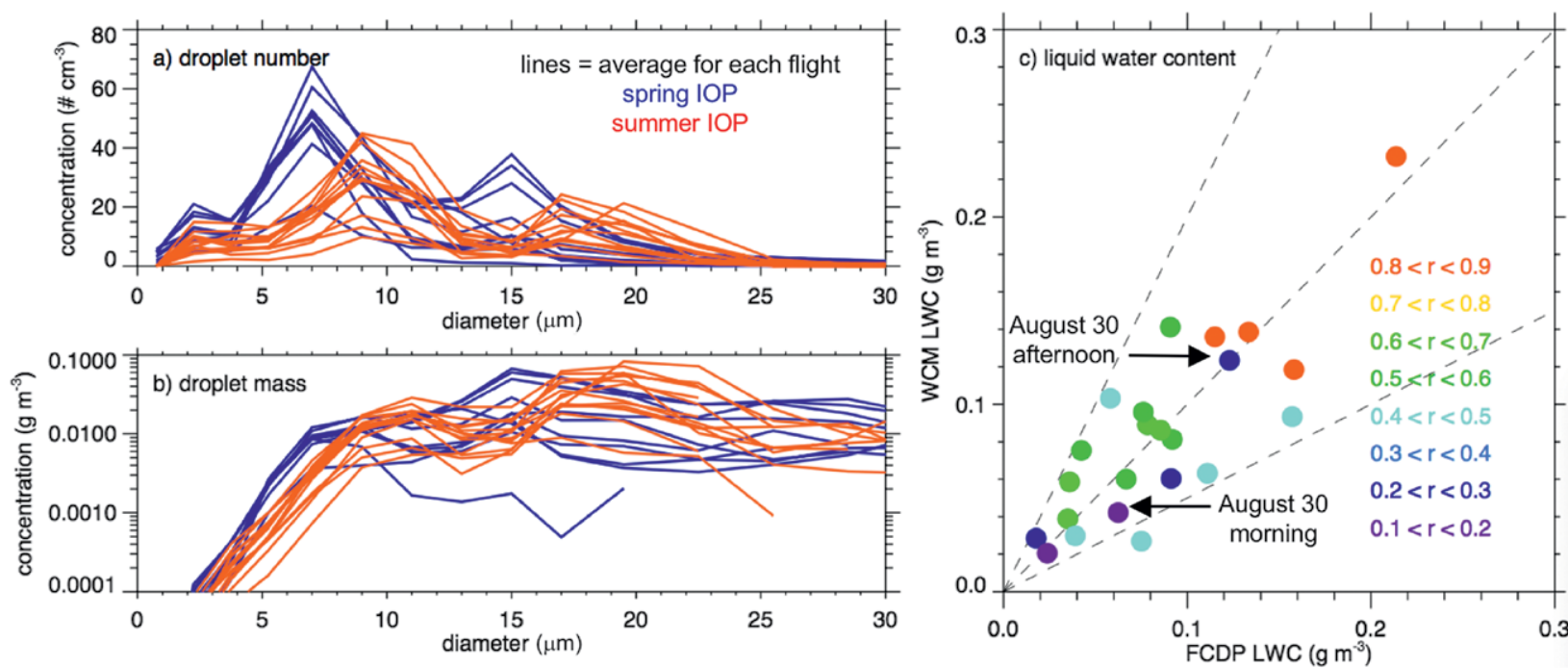

FIG. 5. HI-SCALE cloud statistics from G-I flights during the spring IOPs (blue) on 25 and 27 Apr, and I, 2, 8, II, 16, 18, 19, and 20 May, and the summer IOP (red) on 29 and 30 (2 flights) Aug, and I, 3, 4 (2 flights), 7, 15 (2 flights), 17, 20, and 2I Sep, including (a) average droplet number concentration distribution and (b) average droplet mass concentration distribution. (c) Comparison of the average cloud LWC for each G-I flight measured by the WCM-2000 and derived from the FCDP, where the color denotes the correlation coefficient.

the simulated cloud population is nearly the same during the day because relatively few clouds grow larger during the afternoon. The results in Fig. 4 indicate that there are still some aspects of the LES representation of clouds that need to be improved.
A summary of the overall cloud droplet number and mass distributions measured during HI-SCALE is shown in Figs. 5a and 5b. The average droplet number distributions for all the flights during the spring IOP are similar. The number and mass 
concentrations vary from day to day, especially for droplets larger than $10 \mu \mathrm{m}$. Interestingly, the droplet number and mass distribution during the summer IOP is shifted toward larger sizes with the peak concentrations about $2 \mu \mathrm{m}$ larger than those during the spring IOP. The reason for this shift is unclear; however, Janssen et al. (2011) also note an increase in droplet effective radius between the spring and summer at the Hyytiälä site in Finland. The uncertainty in the droplet size measurements is assessed by comparing the LWC derived from the Fast-Cloud Droplet Probe (FCDP) instrument compared with an independent measurement of LWC from a Multi-Element Water Content System (WCM) instrument, as shown in Fig. 5c. The two measures of LWC differ by less than a factor of 2 and the bias is close to 0 . In general, the correlation between the two instruments increases with increasing LWC. The flights with the highest correlation were on 2 , 16,19 , and 20 May, days with the most extensive cloudiness, ranging from overcast to broken clouds. The results in Fig. $5 c$ suggest that larger uncertainty exists for small clouds with low LWC. We note that the bias in the LWC on 30 August is relatively low, so that measurement uncertainty will not affect the overall conclusion that the LASSO droplet number concentrations were too high.

In terms of cloud-aerosol interactions, we found that smaller cloud droplets were associated with higher CCN concentrations indicative of the Twomey effect (Twomey 1977). In contrast with the Cumulus Humilis Aerosol Processing Study (CHAPS) in which anthropogenic aerosols within the Oklahoma City, Oklahoma, plume were shown to impact the optical properties of shallow clouds (Berg et al. 2011a), preliminary analyses of HI-SCALE data indicated that the cloud droplet number depended weakly on anthropogenic aerosol. This is due, in part, to the measurement strategy that did not target the Oklahoma City plume. As will be shown later, the aerosols sampled were complex and likely originated from a mixture of anthropogenic, biogenic, and biomass burning sources; therefore, additional analyses are needed to determine how $\mathrm{CCN}$ and cloud droplet number are influenced by observed aerosol properties.

Land-atmosphere coupling. In addition to shallow clouds and their effect on the radiation budget, there are often large heterogeneities in land use,

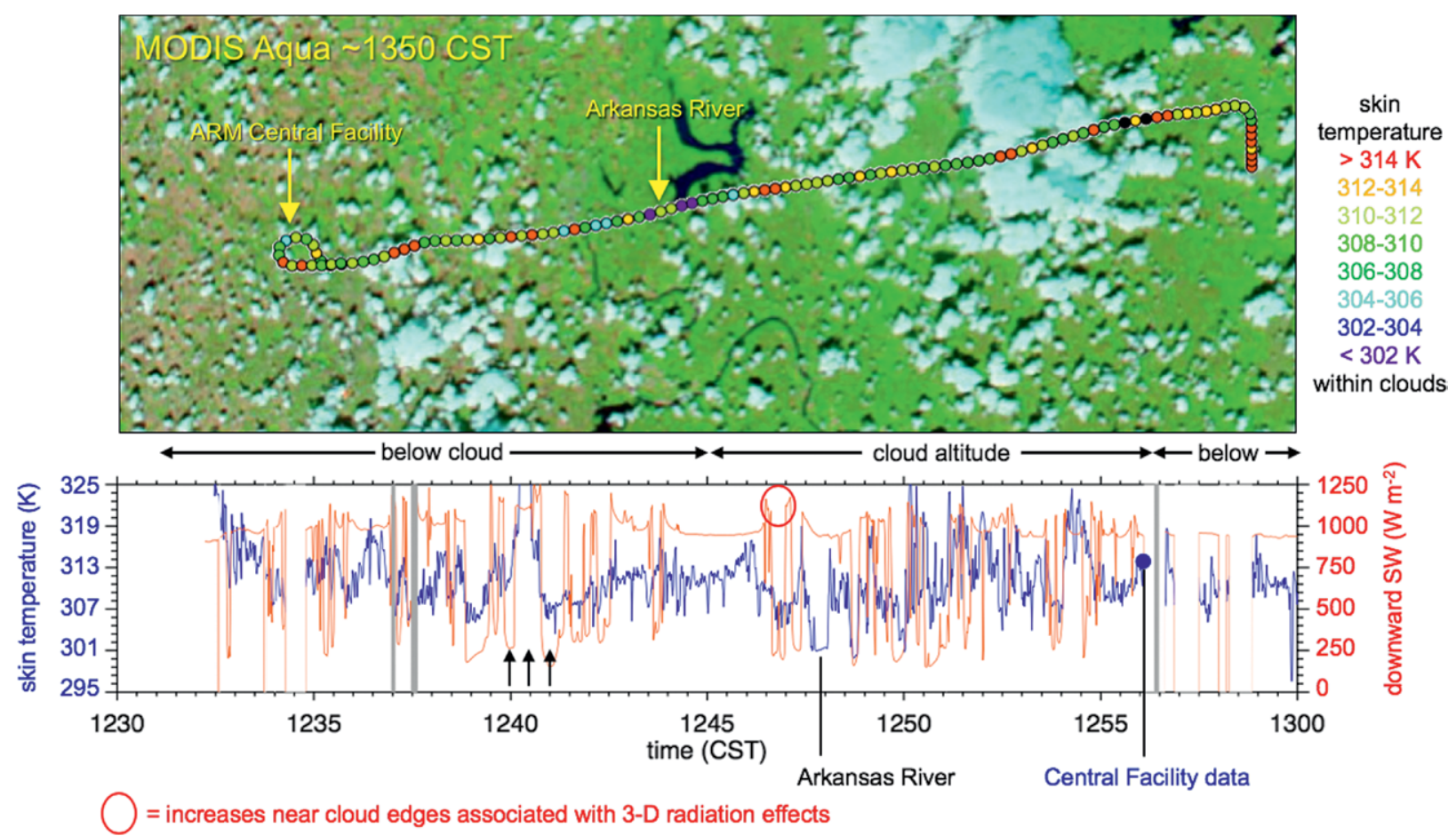

FIG. 6. (bottom) Variability of measured skin temperature (blue) and downward shortwave (SW; red) radiation during the afternoon flight on 30 Aug in relation to (top) the spatial variations of land use and clouds from MODIS bands $2,155,876$, and $670 \mathrm{~nm}$. Data in the top and bottom panels are at I5- and I-s intervals, respectively. Arrows denote example periods when cloud shading reduces skin temperature. Gray shading denotes periods when the G-I was within clouds. The same MODIS false-color image is used as in Fig. 3. 
vegetation, soil moisture, and albedo that influence land-atmosphere coupling that are usually subgrid scale. These heterogeneities and their effect on land-atmosphere coupling, however, are neglected or poorly parameterized and are known to contribute to biases in near-surface temperature and precipitation from weather forecast and climate models (Cheruy et al. 2014; Morcrette et al. 2018), especially over the midlatitude continents.

Figure 6 is an example of subgrid-scale variability in skin temperature (from the infrared thermometer) and downwelling radiation [from the sunshine pyranometer (SPN1), corrected for tilt from the horizontal; Long et al. (2010)] during the afternoon flight on 30 August. Only the first half of the flight is shown when the aircraft was below clouds so that reductions in the shortwave radiation are due to shading by individual cloud elements. Skin temperatures varied by as much as $18^{\circ} \mathrm{C}$ along the flight path and many of the reductions in skin temperature are associated with cloud shading. The arrows in Fig. 6 illustrate one example of cooling by cloud shading, but there are other factors, such as albedo, soil moisture, and soil temperature that influence skin temperature.

Figure 6 also illustrates $3 \mathrm{D}$ radiation effects that are not accounted for by $1 \mathrm{D}$ radiation parameterizations used by forecast models. Neglecting cloud shading and enhancements by $1 \mathrm{D}$ radiation parameterizations could influence boundary layer circulations and the evolution of shallow cloud populations (e.g., Gronemeier et al. 2017; Xiao et al. 2018). The variations of the radiative effects of clouds, such as those shown in Fig. 6, are key measurements needed to critically evaluate simulated cloud properties (e.g., liquid water content, droplet size distribution) in addition to the strength of land-atmosphere interactions and boundary layer mixing.

An example of how land-use variability impacts skin temperature is shown in Fig. 7 for a portion of the G-1 flight on 10 September, a day with no clouds that complicates the interpretation of skin temperature. The G-1 flew along this west-to-east transect three times between 1015 and 1136 CST. Skin temperatures increased in time by as much as $5^{\circ} \mathrm{C}$, but there was no change in temperatures in some sections of the transect. Point A is located over irrigated crop, which is a darker surface but likely had larger soil moisture so that evaporation led to relatively small skin temperatures. As the G-1 crossed over a region of bare fields shown by points $\mathrm{B}$ and $\mathrm{C}$, skin temperatures at $1130 \mathrm{CST}$ increased by $5^{\circ} \mathrm{C}$ over a distance of a few hundred meters. The
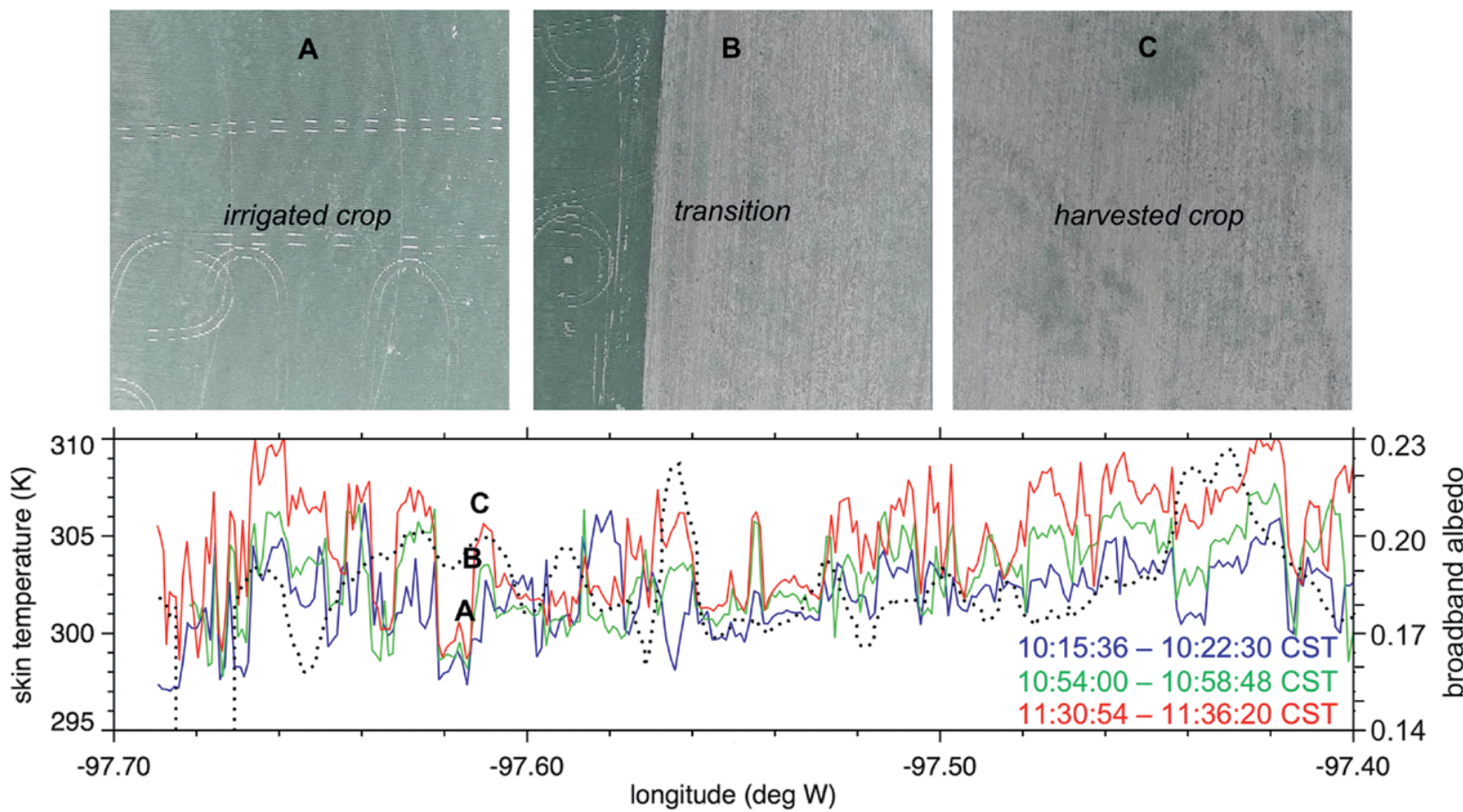

FIG. 7. (bottom) Measured skin temperature associated with land-use variability during three periods on I0 Sep over the same east-to-west transect. Clear-sky conditions were observed on this day during the flight. Letters $A, B$, and C denote times associated with (top) land-use type from the downward-pointing video images. Black dotted line denotes albedo derived from broadband radiation instruments on the G-I between II30:54 and II36:20 CST when the aircraft was within $700 \mathrm{~m}$ of the ground. 
horizontal temperature difference between points $\mathrm{A}$ and $\mathrm{C}$ was $\sim 2^{\circ} \mathrm{C}$ at $1015 \mathrm{CST}$ and increased to $6^{\circ} \mathrm{C}$ in only $45 \mathrm{~min}$. Albedo, derived from the broadband radiation instruments, increased from 0.19 over the irrigated crop to 0.20 over the harvested crop region. The actual change in albedo is likely larger since the field of view from the pyranometers is much larger than the infrared thermometer. While the bare-field region had a slightly larger albedo that would reflect more sunlight, the soil moisture and evapotranspiration was likely smaller than over point $\mathrm{A}$, which led to higher skin temperatures. Consistent with the likely soil moisture gradient, specific humidity aloft decreased from 7.3 to $6.2 \mathrm{~g} \mathrm{~kg}^{-1}$ as the G-1 crossed into the harvested-crop region. This patchiness is repeated as the G-1 passes over the transitions between crop types, grasslands, and forested regions that are even more complicated.

Figure 8 depicts an example of wind profiles and convective boundary layer (CBL) height evolution on 30 August obtained from the new Doppler lidar configuration at the SGP megasite. The CBL height is determined using a threshold value of vertical velocity variance, as described by Berg et al. (2017) and Tucker et al. (2009). A low-level jet formed over the SGP megasite before sunrise, but there were substantial variations in the wind speeds among the sites. The winds were strongest at the southeastern lidar site (E39), while the jet was nearly nonexistent at the northwestern lidar side (E32). For a few hours after 1000 CST, the growth rates of the CBL over the western lidar sites (E32 and E37) were faster than the other three sites. Then, at $1100 \mathrm{CST}$, the CBL grew from 0.8 to $1.8 \mathrm{~km}$ at the southeastern lidar site (E39) in less than an hour. As shown in Fig. 8f, the growth of the CBL slowed after noon but the CBL height varied by as much as $600 \mathrm{~m}$ across the SGP megasite between 1200 and 1600 CST. Variations in CBL height also led to similar variations in cloud base. As expected, the spatial variability in CBL height is reduced on days with stronger synoptic forcing and overcast conditions (not shown).

To demonstrate how G-1 measurements can be used to supplement and expand routine ARM measurements, Fig. 9a shows the frequency distributions of vertical velocity using both the Central Facility Doppler lidar and nearby G-1 transects during the late morning of 30 August. At this time, stronger updrafts were observed more frequently below the middle of the convective boundary layer $\left(z / z_{i}<0.45\right)$. a) E32

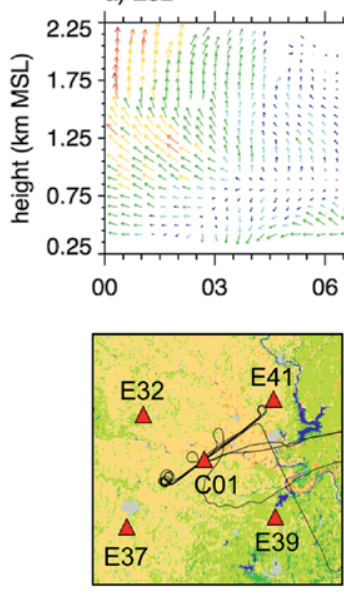

d) E37

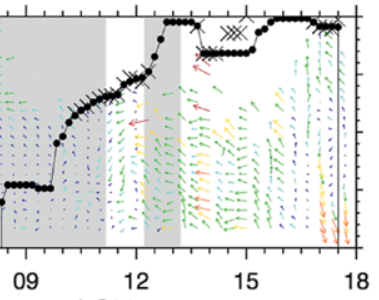

b) E41
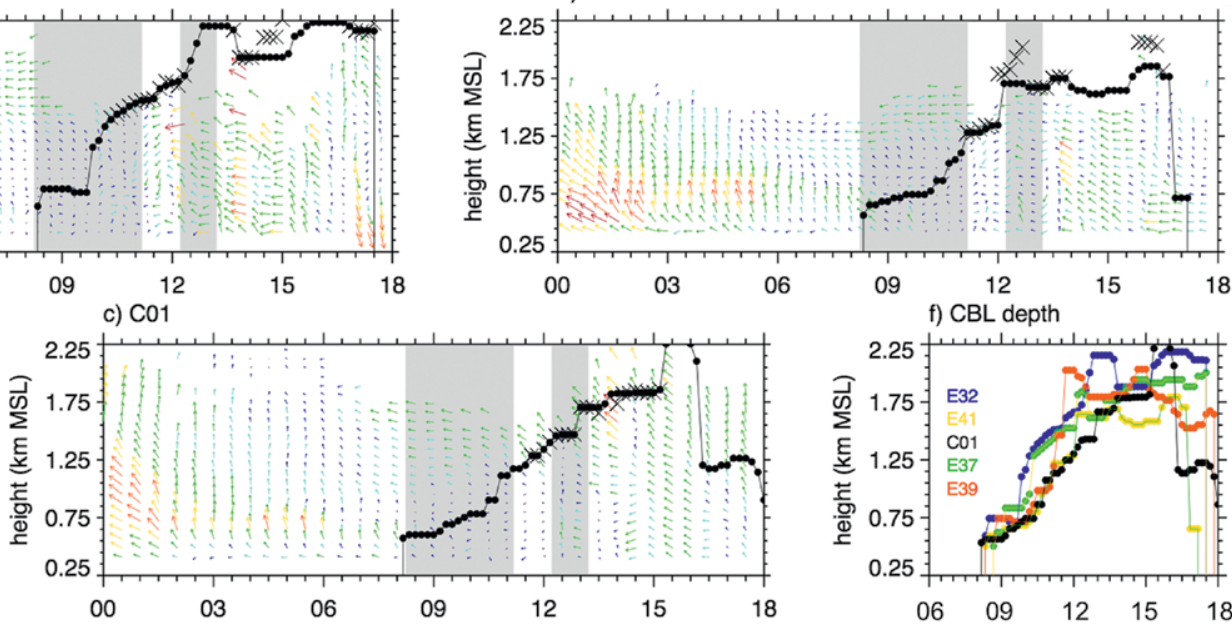

e) E39
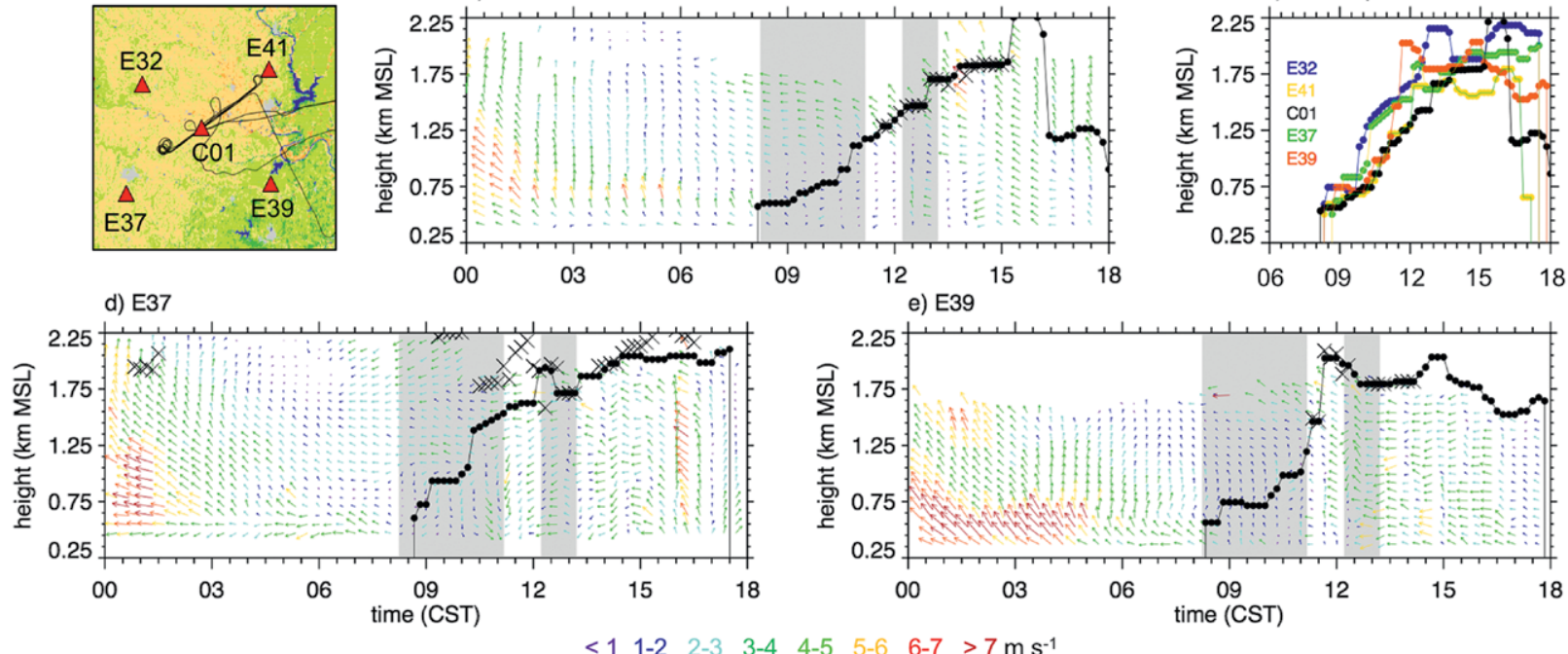

Fig. 8. Doppler lidar wind profiles measured on 30 Aug at the (a) E32, (b) E4I, (c) C0I, (d) E37, and (e) E39 sites along with derived CBL depth (black circles) and cloud-base height $X$. (f) A direct comparison of the CBL depth among the five Doppler lidars is shown. Gray shading denotes the two G-I sampling periods. 
a) Frequency of $w$ as a function of height

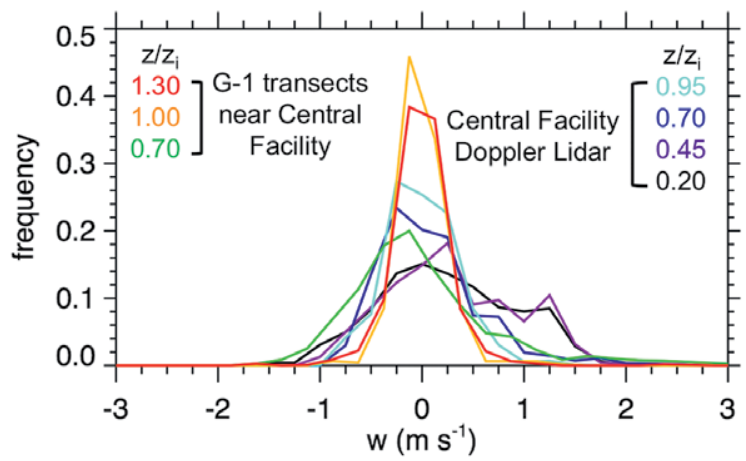

b) Frequency of $w$ as a function of space

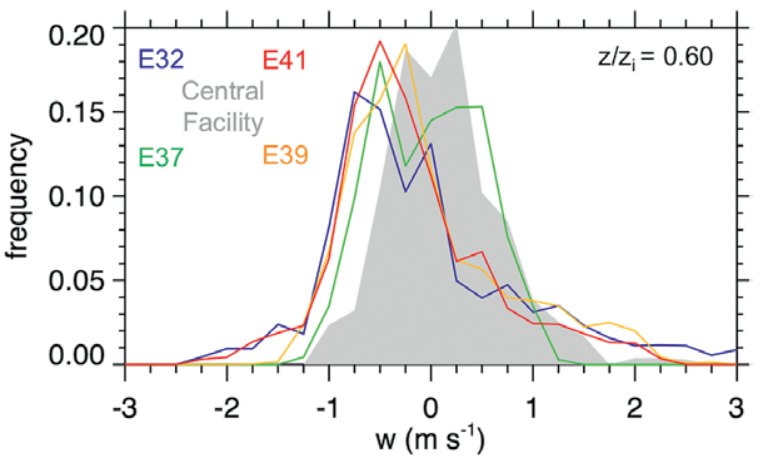

FIG. 9. Frequency of vertical velocity $w$ between 1006 and II36 CST as a function of (a) height using data from the Central Facility Doppler lidar and the G-I transects close to the Central Facility and (b) space using data from all five Doppler lidars. Here, $z / z_{i}$ is the normalized convective boundary layer height, where $z_{i}$ is taken from Doppler lidar estimates (Fig. 9).

While the Doppler lidar and G-1 distributions are similar for $z / z_{i}=0.7$, the differences likely result from the spatial aircraft flight path that samples convective eddies that may not pass directly over the Central Facility. The G-1 measurements show that vertical velocities are usually within $0.25 \mathrm{~m} \mathrm{~s}^{-1}$ of zero at and above the boundary layer top at $z / z_{i}=1.0$ and 1.3, respectively. As expected, the vertical velocity distribution within the convective boundary layer broadens during the afternoon (not shown) as convective eddies grow in strength. Figure $9 \mathrm{~b}$ shows the spatial variability over the SGP site in the vertical velocity statistics at this time. The data shown in Fig. 9 still need to be coupled to the surface flux and other data to better understand the factors contributing to the observed variability in boundary layer properties over the SGP site. Coupling the surfacebased (Berg et al. 2017) and G-1 measurements will also provide a means of more completely evaluating the performance of LES models.

In summary, the HI-SCALE and reconfigured ARM measurements provide a wealth of information that can be used to examine how spatial variations in the mean and turbulent boundary layer properties change with time and depend on local land use and soil properties. Coupling the meteorological and soil observations with highresolution $(30 \mathrm{~m})$ land cover datasets, such as the National Land Cover Database (NLCD; Homer et al. 2015) and CropScape (Han et al. 2012), will reveal how boundary layer turbulence and shallow clouds are influenced by heterogeneity in albedo and other surface properties. Figures 6-9 only scratch the surface of the data available for quantifying the relationships that affect land-atmosphere interactions around the SGP megasite.
Variability of aerosol and their precursors. Since the SGP megasite is a rural location, it is often thought of as a "clean" continental site in terms of aerosols. However, Parworth et al. (2015) found that the monthly averaged concentrations varied substantially between 2 and $14 \mu \mathrm{g} \mathrm{m}^{-3}$ during 2011, reflecting multiday and seasonal variations in aerosol from anthropogenic, biogenic, and biomass burning sources and the impact of meteorology on secondary formation of organic and inorganic aerosols. The temporal variation of aerosol concentrations during the spring IOP obtained from the HR-ToF-AMS at the Central Facility during the spring IOP is shown in Fig. 10a. Total nonrefractory concentration varied from near 0 to almost $8 \mu \mathrm{g} \mathrm{m}^{-3}$ with an average of $2.6 \mu \mathrm{g} \mathrm{m}^{-3}$ over the 26 -day period. The temporal variations in organic matter $(\mathrm{OM})$, sulfate $\left(\mathrm{SO}_{4}\right)$, nitrate $\left(\mathrm{NO}_{3}\right)$, and ammonium $\left(\mathrm{NH}_{4}\right)$ are not identical, since their precursors often originate from different sources. OM comprised the largest fraction (Fig. 10b) with an average of 70\% of the nonrefractory mass during the spring IOP; however, there were periods where inorganics were greater than $50 \%$ of the total mass. The concentrations of $\mathrm{OM}, \mathrm{SO}_{4}, \mathrm{NO}_{3}$, and $\mathrm{NH}_{4}$ shown in Fig. 10a are also very close to those obtained from the G-1 when the aircraft passed over the Central Facility within the boundary layer (not shown). Mostly sunny skies, warm temperatures, and southerly winds (Figs. 10c,d) that favor photochemistry and the transport of emissions from urban areas (Oklahoma City and cities in Texas) were associated with larger aerosol concentrations between 25-27 April and 6-9 May. Larger aerosol concentrations, such as those on 16 May and between 19 and 20 May, were also associated with easterly winds even though the maximum daytime temperatures were below $20^{\circ} \mathrm{C}$. The smallest 


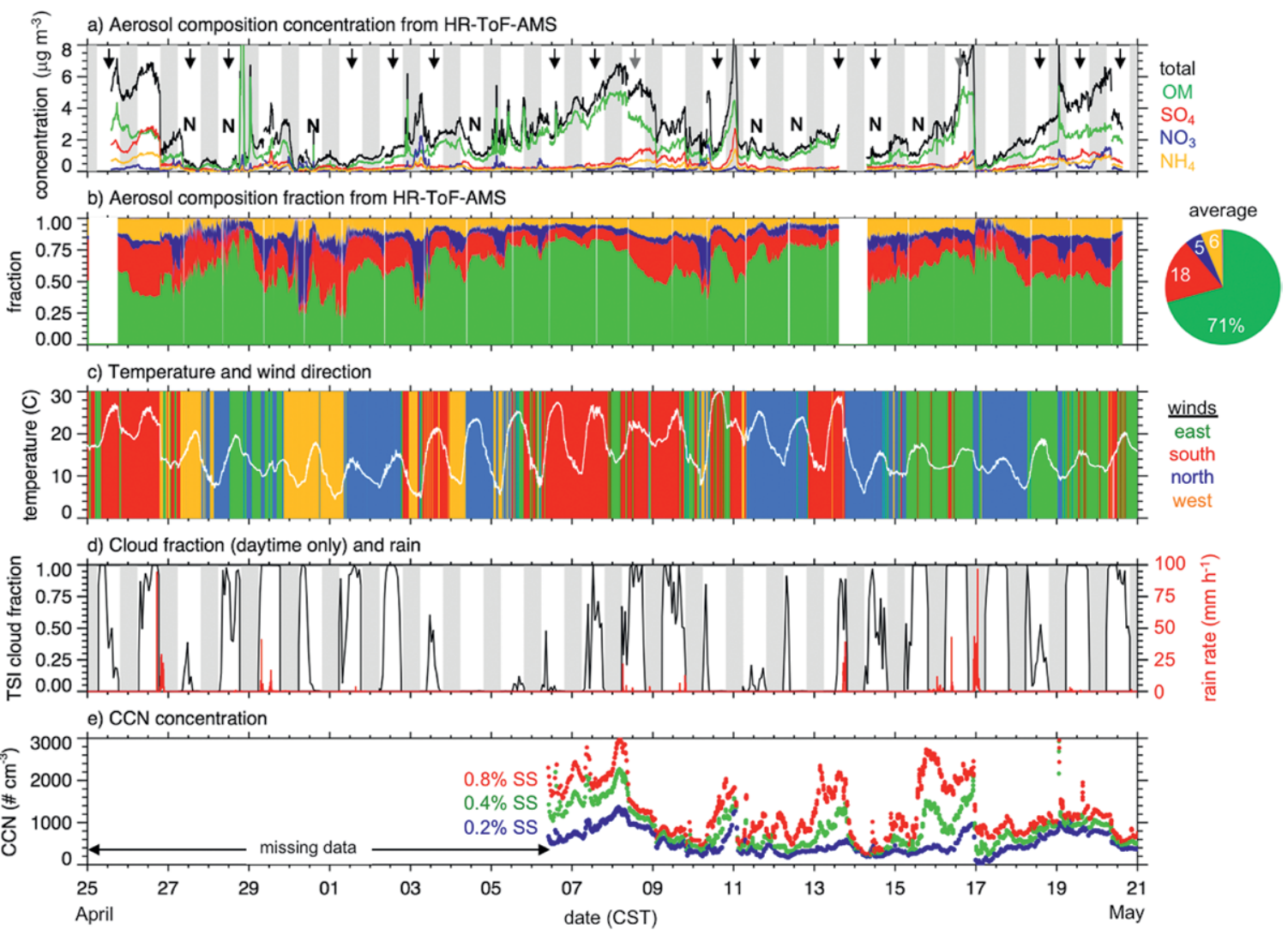

FIG. 10. Temporal variation in (a) aerosol composition, (b) composition fraction, (c) temperature (white line) and wind direction (color shading), (d) cloud fraction (black line) and rain rate (red line), and (e) CCN concentration at three supersaturations (SS) at the ground site during the spring IOP. Arrows in (a) denote G-I aircraft flight days and $N$ denotes days with new particle formation events, while gray shading denotes nighttime periods.

aerosol concentrations usually occurred on days with northerly or westerly winds, which usually transport cleaner air over the SGP megasite.

Ching et al. (2016) and other studies have shown that errors in CCN when using Kohler theory and assuming an internal mixture of aerosols were often $\sim 15 \%$, but could be as high as $45 \%$ depending on the type of aerosol population. Figure 11a illustrates the mixing state of particle populations sampled by miniSPLAT for the flight on 25 April. To simplify the interpretation of chemical composition obtained from miniSPLAT, aerosol compositions have been grouped into 10 particle classes and averaged over flight legs. On this day, about $90 \%$ of the aerosols sampled in the boundary layer were composed of four classes: mostly $\mathrm{SO}_{4}$ mixed with $\mathrm{NO}_{3}$ and $\mathrm{OM}$, mostly $\mathrm{NO}_{3}$ mixed with $\mathrm{OM}$, oxygenated $\mathrm{OM}$, and mostly OM mixed with biomass burning aerosol. The remaining aerosols were an external mixture of soot, mostly $\mathrm{OM}$ mixed with $\mathrm{SO}_{4}$, biomass burning, soil, dust, and SOA from isoprene epoxydiols (IEPOX) chemistry (Paulot et al. 2009).
Figure 11a also illustrates changes in aerosol composition with height. While the aerosol compositions among the flight tracks within the boundary layer are similar, the flight tracks at higher altitudes have a larger fraction of $\mathrm{SO}_{4}$ and $\mathrm{NO}_{3}$ mixture classes than those at lower altitudes. The relative fraction of particle classes of interstitial aerosols within and outside of clouds at cloud altitudes was in between those for boundary layer aerosol and the cloud droplet residuals. Above clouds, aerosol concentrations decreased significantly and the relative contribution of soot, biomass burning, and dust was higher than in the boundary layer or in cloud droplet residuals. The two columns denoted by "within CVI" indicate the particle classes obtained from cloud droplet residuals. They not only reflect the type of aerosols that preferentially acted as $\mathrm{CCN}$, but the higher fraction $\mathrm{SO}_{4}$ and $\mathrm{NO}_{3}$ was also likely due to formation by aqueous chemistry within the cloud droplets (e.g., Seigneur and Saxena 1988; Lee and Lind 1986; Berg et al. 2009; Shrivastava et al. 2013). As shown in Fig. 11b, cloud droplet residuals were also $\sim 100 \mathrm{~nm}$ 
larger than interstitial aerosols in the boundary layer and between clouds, which is indicative of aqueous chemistry that can increase cloudborne $\mathrm{SO}_{4}, \mathrm{NO}_{3}$, and other species within cloud droplets (Ogren et al. 1989). Since OM and soot are less hygroscopic than $\mathrm{SO}_{4}$ and $\mathrm{NO}_{3}$ (Petters and Kreidenweis 2007), the lower fraction of $\mathrm{OM}$ and soot in the droplet residuals is likely due to fewer of those aerosols acting as $\mathrm{CCN}$. However, one class of OM with signatures of IEPOX was much higher in the cloud residuals (Fig. 11a), suggesting that aqueous organic chemistry (e.g., Ervens et al. 2011) also occurred within cloud droplets. The changes in particle phase organics were consistent with changes in biogenic trace gas precursors measured by the HRToF-CIMS (not shown). Aqueous chemical processing is thought to be an important source of OM in the atmosphere (e.g., McNeill 2015), but the key chemical pathways are not fully understood and direct observations have been lacking.

As seen from two of the particle classes from the miniSPLAT measurements in Fig. 11a, a significant fraction of OM has mass spectra indicative of biomass burning. Some particles are primarily smoke, while other smoke particles also contain other types of OM. The relative contribution of biomass burning varies significantly from day to day, and on some days, it is the primary source (not shown).

Measurements from the airborne HR-ToF-CIMS instrument can be used to identify gas-phase precursors of biogenic SOA; therefore, an example of the HT-ToF-CIMS and HR-ToF-AMS measurements on 7 May as well as the IOP averages are shown in Fig. 12 in terms of percentiles. Larger amounts of isoprene (not shown) and isoprene products including IEPOX and isoprene hydroxy hydroperoxides (ISOPOOH) were the highest over the regions with the highest percentage of deciduous trees (including oak trees), as expected (Fig. 12a). The southerly winds suggest that the higher OM along the western third of the southwest-to-northeast transects is produced mostly by anthropogenic emissions from Oklahoma City. The winds also suggest that the rest of the transects were likely a mixture of anthropogenic and biogenic emissions, which is important because several studies have found that biogenic SOA formation is enhanced in the presence of anthropogenic precursors (e.g., Carlton et al. 2010; Shilling et al. 2013). On average, the gas-phase products of isoprene (IEPOX + ISOPOOH) were generally larger during the summer IOP (Fig. 12b). The median isoprene product concentration during the summer IOP was a little over an order of magnitude higher than during the spring IOP. This also suggests that photochemistry was more active during the summer IOP, which would have converted more isoprene into isoprene products and SOA. Seasonal differences in terpene concentrations aloft between the two IOPs were far less.

It is important to note that the aircraft measurements for fast-reacting trace gases are likely to be different from those obtained near the ground at Central Facility (not shown). In contrast with the G-1 isoprene measurements that were larger during the spring IOP, average isoprene concentrations at the ground were 0.26 and $0.51 \mathrm{ppb}$ during the spring and summer IOPs, respectively. The measurements in 

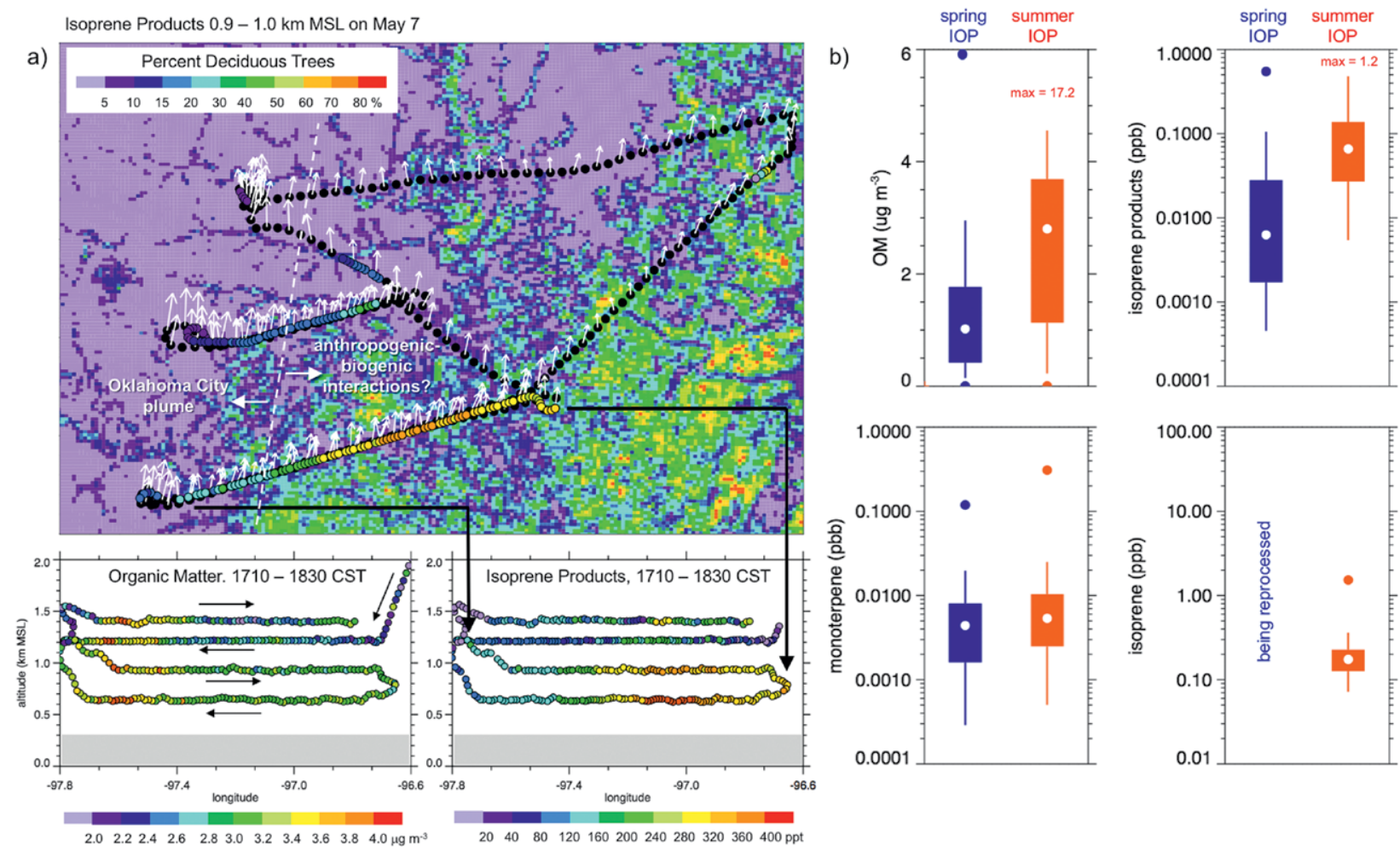

FIG. I2. (a) Spatial and temporal variability of isoprene products measured by Chemical lonization Mass Spectrometer (CIMS) and OM measured by the AMS on 7 May as well as (b) percentiles of OM, isoprene products, monoterpene, and isoprene for all flights during the spring (blue) and summer (red) IOPs. In (a), black dots represent missing isoprene product data. In (b), open circles, box, lines, and filled circles denote the median, 25th-75th percentiles, 5th-95th percentiles, and minimum and maximum values, respectively.

Fig. 12 suggest that processes affecting biogenic SOA differ by season; however, additional analyses of mass spectra are needed to infer the relative contribution of the biogenic source on OM and identify the specific chemical pathways.

New particle formation. NPF events (Kulmala et al. 2004) perturb the growth rate and number of aerosols, thereby influencing CCN concentrations (e.g., Kuang et al. 2009; Pierce and Adams 2009) and ultimately cloud properties. Various chemical pathways associated with NPF involving sulfuric acid and/or other trace gases have been proposed (e.g., Almeida et al. 2013; Kulmala et al. 1998; Riccobono et al. 2014), but the relative importance of each pathway is still uncertain. Using measurements from the New Particle Formation Study (NPFS) at SGP during April and May of 2013, Hodshire et al. (2016) found three distinct chemical growth pathways associated with 1) primarily organics, 2) primarily sulfuric acid and ammonia, or 3) primarily sulfuric acid and associated bases and organics. In addition, Chen et al. (2018) used a tethered balloon during one event of NPFS to show that particles were likely formed aloft, and then quickly mixed throughout the boundary layer where they are observed by ground-based instruments.

The HI-SCALE measurements provide insights into the spatial extent of NPF events, as shown in Fig. 13 that have been rarely observed previously. The G-1 flights on 11 and 17 September coincidentally measured large concentrations of aerosols smaller than $10 \mathrm{~nm}$ at the same time surface measurements captured NPF events. On 11 September (Fig. 13a), large concentrations of aerosols smaller than $10 \mathrm{~nm}$ were observed along much of the G-1 flight path in the boundary layer around and to the southeast of the SGP megasite. The southerly winds suggest that precursor gases from Oklahoma City may have contributed to the NPF event that occurs over a relatively large region. The regions with the largest aerosol concentrations smaller than $10 \mathrm{~nm}$ and the light winds on 17 September (Fig. 13b) suggest the NPF event was likely associated with local emissions, such as those from power plant and oil refinery (Fig. 2) plumes of $\mathrm{SO}_{2}$ emissions close to the SGP megasite. Shallow cumulus formed on this day, so it will be interesting to couple the evolving size distribution 

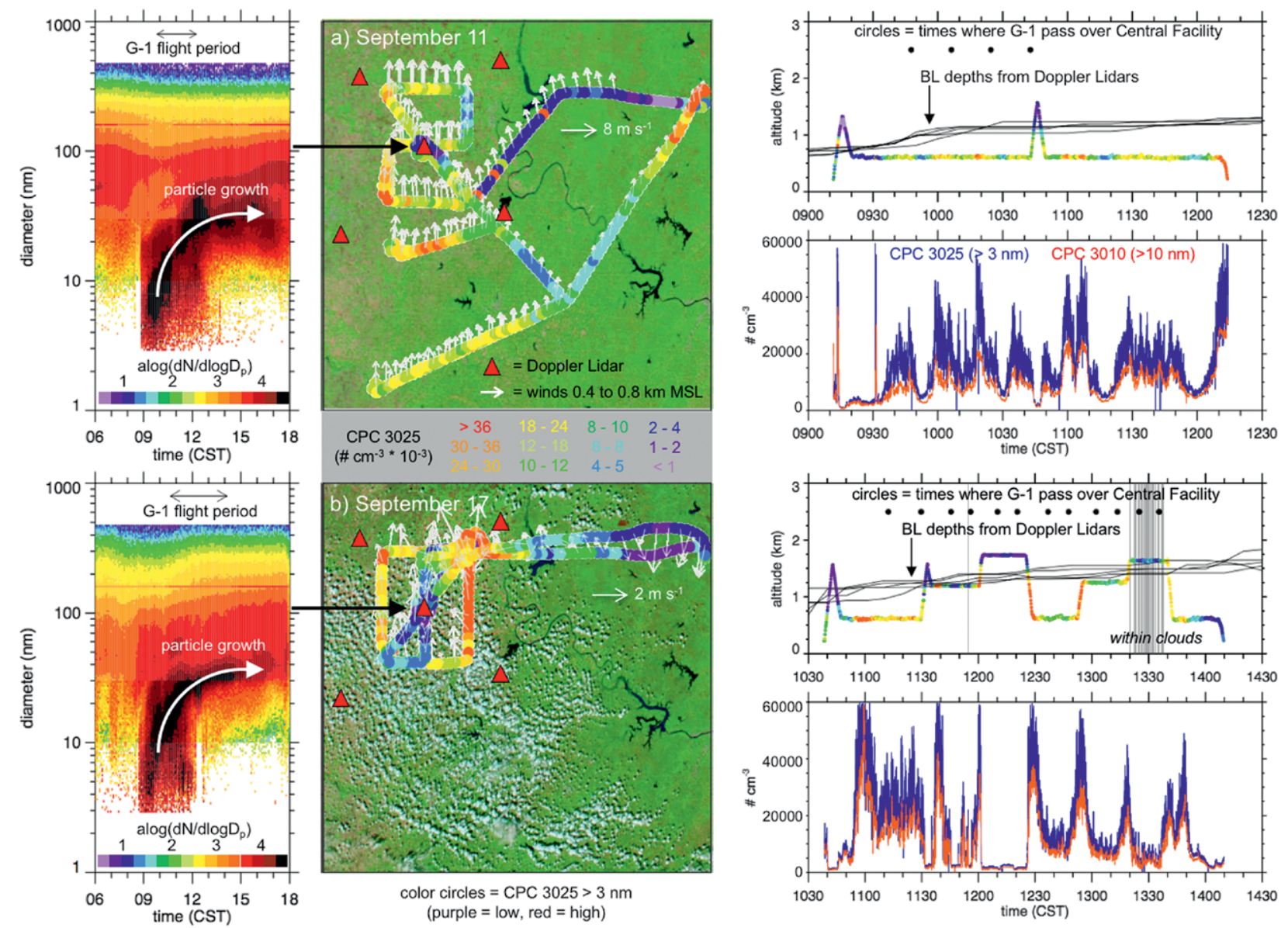

Fig. 13. New particle formation events on (a) II and (b) 17 Sep showing (left) the particle number distribution from the SMPS instrument at the Central Facility, (middle) the spatial variability of the total particle number concentration near the SGP site measured by the G-I aircraft, and (right) the temporal variation of particle number concentration $>3$ (blue) and $>10 \mathrm{~nm}$ (red) measured by the $\mathrm{G}-\mathrm{I}$ aircraft (right panels).

measurements with CCN to determine whether NPF had an impact on cloud properties.

Totals of 20 and 6 NPF events were observed during the 28-day spring and summer IOPs, respectively, although several other interrupted or partial events also occurred. This number of 20 events is somewhat more than the $13 \mathrm{NPF}$ events observed over a 36-day period during the NPFS in 2013. The days with NPF events for the spring IOP are shown in Fig. 10a, and all of them occur during periods of relatively small fine mode aerosol concentrations because those aerosols compete for condensable trace gases and, thus, inhibit NPF.

\section{ANALYSISAND MODELING OPPORTUNITIES. The wealth of meteorological,} cloud, radiation, trace gas, and aerosol measurements collected during HI-SCALE will enable a more holistic understanding of the life cycle of shallow clouds that couples cloud macrophysical and microphysical properties to land surface properties, ecosystems, and aerosols.

Listed next are a few of the science questions that can be addressed by using HI-SCALE and other ARM measurements.

Shallow convective clouds.

- What controls the evolution of shallow convective cloud populations and what are the factors that control whether some clouds transition to deeper convection? This challenging question needs to be addressed by multiple data and modeling analyses. For example, the impact of profiles of temperature, humidity, and winds on cloud buoyancy needs to be assessed by combining the aircraft and routine ARM measurements in conjunction with spatial variations in skin temperature, soil moisture, and fluxes of sensible and latent heat.

- What is the relative role of local and regional-scale processes on the initiation and life cycle of shallow 
convective clouds? HI-SCALE cases and their cloud populations can be divided into those with weaker and stronger synoptic conditions. To assess the importance of local forcing on clouds, modeling studies that have either uniform or variable surface properties for specific regional environmental conditions can be compared with each other and with the measurements. Then, the regional environmental conditions can be changed with fixed local surface properties to assess whether they enhance or suppress the impact of local forcing on clouds.

- Are 3D radiation effects important when representing shallow cloud populations in models? Radiation and cloud measurements from both the aircraft and ground instrumentation can be used to evaluate characteristics of cloud populations predicted by LES models that employ either $1 \mathrm{D}$ or 3D radiation parameterizations.

\section{Land-atmosphere-cloud coupling.}

- How do heterogeneities in vegetation, soil moisture, surface albedo, and downwelling radiation affect surface sensible and latent heat fluxes and subsequently the subgrid-scale variability of temperature, humidity, vertical velocity, and shallow clouds? High-resolution land surface, soil moisture, and radiation datasets need to be integrated to determine whether variabilities in those properties influence the observed spatiotemporal variations in surface sensible and latent heat fluxes. Variations in aircraft measurements of temperature, humidity, vertical velocity, and clouds can be quantified over areas of similar size as model grid cells to quantify subgrid-scale variability, which in turn can be related back to variations in surface sensible and latent heat fluxes.

- Are simulations of surface temperature and humidity predicted reasonably well for the right reasons? Near-surface temperature and humidity observations are frequently used to evaluate model performance, but simulated conditions in the soil and at the ground are rarely assessed. The SGP megasite and field campaign observations provide a means to better assess the deficiencies in model representations of land-atmosphere interactions that subsequently impact predictions of turbulence mixing and convective boundary layer growth.

\section{Aerosol life cycle.}

- How do factors such as new particle formation, secondary organic aerosol formation, and aerosol growth from nanoparticle to accumulation mode size affect CCN concentrations? Temporal variations in aerosol size [e.g., Scanning Mobility Particle Sizer (SMPS) and FIMS] and composition (e.g., HR-ToF-AMS) from both the ground and aircraft measurements can be correlated with CCN to determine the relative roles of aerosol concentration and hygroscopicity as a function of size on the observed $\mathrm{CCN}$ concentrations and differences in CCN for periods with or without NPF events.

- Do spatial and temporal variations in the aerosol mixing state significantly affect $C C N$ ? CCN closure studies based on an internal mixing assumption will demonstrate to what extent and under what conditions $\mathrm{CCN}$ derived from theory and aircraft measurements of size and bulk composition agrees with the CCN measurements. Repeating the closure with detailed miniSPLAT measurements will reveal whether accounting for more complex mixing states is important for CCN.

- What precursors and chemical reactions contribute to biogenic SOA, and how do heterogeneities in the boundary layer and vegetation affect the emission rate of biogenic VOCs? The chemical pathways associated with the production of biogenic SOA can be determined by evaluating individual chemical reactions within model experiments that are verified using CIMS and other measurements.

- What is the impact of organic and inorganic aqueous chemistry on the budget of aerosols, and how does cloud processing affect the properties of CCN? Evidence of cloud processes of aerosols can be obtained by combining the CIMS and miniSPLAT measurements and comparing interstitial and cloud-borne samples. Modeling studies that track air parcels will shed light on how cloud processing affects CCN properties of interstitial aerosol populations resulting from evaporated cloud droplets.

The temporal and spatial variability of many measurements collected during HI-SCALE will be suitable for evaluating and improving cloud-resolving LES models $(\Delta x=10-100 \mathrm{~m})$, cloud-scale-resolving mesoscale models $(\Delta x=1-10 \mathrm{~km})$, and regional-toglobal-scale models $(\Delta x>10 \mathrm{~km})$. LES modeling is an important tool needed to synthesize numerous measurement types available during HI-SCALE, obtain new process-level understanding, and form the basis of developing and testing new parameterizations suitable for spatial scales used by the next generation of forecast and climate models. However, LES models will need to be modified to include more complex treatments of boundary conditions and surface heterogeneity to adequately represent 
a wider range of real-world conditions. HI-SCALE provided critical in situ field measurements needed to evaluate new parameterizations of land-atmosphere interactions, boundary layer mixing, aerosols, and convection so that the life cycle of shallow convective clouds, their transition to deeper convection, and their subgrid-scale heterogeneity can be better represented in mesoscale models. Carefully designed model experiments coupled with measurements will help us to understand and quantify how the feedbacks between clouds, land-atmosphere interactions, and aerosols affect the overall life cycle of shallow convective cloud populations.

ACKNOWLEDGMENTS. HI-SCALE would not have been possible without the contributions of many individuals including the G-1 flight crew (M. Hubbell, C. Eveland, M. Crocker, P. Carroll, J. Ray, and R. Hone), the ARM SGP support staff (N. Hickmon and M. Rische), and other participating scientists (S. Hering, A. Kalukin, and H Stark). G. Kulkarni provided additional processing of the $\mathrm{CCN}$ data from the Central Facility. The HI-SCALE field campaign was supported by the Atmospheric Radiation Measurement (ARM) Climate Research Facility and the Environmental Molecular Sciences Laboratory (EMSL) through projects 48804 and 49297, both are U.S. Department of Energy (DOE) Office of Science User Facilities sponsored by the Office of Biological and Environmental Research. The ground deployment of an HR-ToF-AMS and SPLAT was supported by EMSL. This research was supported by the Atmospheric System Research (ASR) program as part of the DOE Office of Biological and Environmental Research under PNNL project 57131. James Smith was supported by DOE grant DE-SC0019000. MODIS images were provided through NASA's Land, Atmosphere Near Real-Time Capability for EOS (LANCE, https://earthdata .nasa.gov/earth-observation-data/near-real-time). The Oklahoma Mesonet is operated by the Oklahoma Climatological Survey. Pacific Northwest National Laboratory is operated by DOE by the Battelle Memorial Institute under Contract DE-A06-76RLO 1830. Data used in this manuscript are available from the ARM data archive (www.arm.gov/data and www.arm.gov/research /campaigns/aaf20I6hiscale).

\section{REFERENCES}

Almeida, J., and Coauthors, 2013: Molecular understanding of sulphuric acid-amine particle nucleation in the atmosphere. Nature, 502, 359-363, https://doi .org/10.1038/nature12663.

ARM, 2014: Atmospheric Radiation and Measurement Climate Research Facility decadal vision.
ARM Rep. DOE/SC-ARM-14-029, Office of Science, Department of Energy, 21 pp., www.arm .gov/publications/programdocs/doe-sc-arm-14-029 .pdf.

Berg, L. K., and E. I. Kassianov, 2008: Temporal variability of fair-weather cumulus statistics at the ACRF SGP site. J. Climate, 21, 3344-3358, https:// doi.org/10.1175/2007JCLI2266.1.

- , and Coauthors, 2009: Overview of the Cumulus Humilis Aerosol Processing Study (CHAPS). Bull. Amer. Meteor. Soc., 90, 1653-1667, https://doi .org/10.1175/2009BAMS2760.1.

—, C. M. Berkowitz, J. C. Barnard, G. Senum, and S. R. Springston, 2011a: Observations of the first aerosol indirect effect shallow cumuli. Geophys. Res. Lett., 38, L03809, https://doi.org/10.1029/2010GL046047.

— E. I. Kassianov, C. N. Long, and D. L. Mills, 2011b: Surface summertime radiative forcing by shallow cumuli at the Atmospheric Radiation Measurement Southern Great Plains site. J. Geophys. Res., 116, D01202, https://doi.org/10.1029/2010JD014593.

_-, M. Shrivastava, R. C. Easter, J. D. Fast, E. G. Chapman, and Y. Liu, 2015: A new WRF-Chem treatment for studying regional-scale impacts of cloud processes on aerosol and trace gases in parameterized cumuli. Geosci. Model Dev., 8, 409-429, https://doi .org/10.5194/gmd-8-409-2015.

— , R. K. Newsom, and D. D. Turner, 2017: Year-long vertical velocity statistics derived from Doppler lidar in the continental convective boundary layer. J. Appl. Meteor. Climatol., 56, 2441-2454, https://doi .org/10.1175/JAMC-D-16-0359.1.

Boucher, O., and Coauthors, 2013: Clouds and aerosols. Climate Change 2013: The Physical Science Basis, T. F. Stocker et al., Eds., Cambridge University Press, 571-657.

Canagaratna, M. R., and Coauthors, 2007: Chemical and microphysical characterization of ambient aerosols with the aerodyne aerosol mass spectrometer. Mass Spectrom. Rev., 26, 185-222, https://doi.org/10.1002 /mas.20115.

Carlton, A. G., R. W. Pinder, P. V. Bhave, and G. Pouliot, 2010: To what extent can biogenic SOA be controlled? Environ. Sci. Technol., 44, 3386-3380, https://doi .org/10.1021/es903506b.

Chen, H., and Coauthors, 2018: Vertically resolved concentration and liquid water content of atmospheric nanoparticles at the US DOE Southern Great Plains site. Atmos. Chem. Phys., 18, 311-326, https://doi .org/10.5194/acp-18-311-2018.

Cheruy, F., J. L. Dufresne, F. Hourdin, and A. Ducharne, 2014: Role of clouds and land-atmosphere coupling in midlatitude continental summer warm biases 
and climate change amplification in CMIP5 simulations. Geophys. Res. Lett., 41, 6493-6500, https://doi .org/10.1002/2014GL061145.

Ching, J., R. A. Zaveri, R. C. Easter, N. Riemer, and J. D. Fast, 2016: A three-dimensional sectional representation of aerosol mixing state for simulating optical properties and cloud condensation nuclei. J. Geophys. Res., 121, 5912-5929, https://doi .org/10.1002/2015JD024323.

Clothiaux, E. E., T. P. Ackerman, G. C. Mace, K. P. Moran, R. T. Marchand, M. A. Miller, and B. E. Martner, 2000: Objective determination of cloud heights and radar reflectivities using a combination of active remote sensors at the ARM CART sites. J. Appl. Meteor., 39, 645-665, https://doi .org/10.1175/1520-0450(2000)039<0645:ODOCHA $>2.0 . \mathrm{CO} ; 2$.

Dirmeyer, P. A., R. D. Koster, and Z. Guo, 2006: Do global models properly represent the feedback between land and atmosphere? J. Hydrometeor., 7, 1177-1198, https://doi.org/10.1175/JHM532.1.

Ervens, B., B. J. Turpin, and R. J. Weber, 2011: Secondary organic aerosol formation in cloud droplets and aqueous particles (aqSOA): A review of laboratory, field and model studies. Atmos. Chem. Phys., 11, 11 069-11 102, https://doi.org/10.5194/acp-11 -11069-2011.

Essery, R., M. Best, R. Betts, P. Cox, and C. M. Taylor, 2003: Explicit representation of subgrid heterogeneity in a GCM land surface scheme. J. Hydrometeor., 4, 530-543, https://doi.org/10.1175/1525-7541(2003) 004<0530:EROSHI>2.0.CO;2.

Fan, J., Y. Wang, D. Rosenfled, and X. Liu, 2016: Review of aerosol-cloud interactions: Mechanisms, significance, and challenges. J. Atmos. Sci., 73, 4221-4252, https://doi.org/10.1175/JAS-D-16-0037.1.

Gronemeier, T., F. Kanani-Suhring, and S. Raasch, 2017: Do shallow cumulus clouds have the potential to trigger secondary circulations via shading. Bound.Layer Meteor., 162, 143-169, https://doi.org/10.1007 /s10546-016-0180-7.

Gustafson, W. I., A. M. Vogelmann, X. Cheng, S. Endo, B. Krishna, Z. Li, T. Toto, and H. Xiao, 2016: Description of the LASSO alpha 1 release. ARM Rep. DOE/ SC-ARM-TR-194, Office of Science, Department of Energy, 163 pp., https://doi.org/10.2172/1373564.

,,,,,,------- , and - , 2017a: Description of the LASSO alpha 2 release. ARM Rep. DOE/SC-ARM-TR-199, Office of Science, Department of Energy, 209 pp., https://doi .org/10.2172/1376727.

,,,,,,------- , and,$- 2017 \mathrm{~b}$ :

Recommendations for the implementation of the
LASSO workflow. ARM Rep. DOE/SC-ARM-17-031, Office of Science, Department of Energy, 62 pp., https://doi.org/10.2172/1406259.

Han, W., Z. Yang, L. Di, and R. Mueller, 2012: CropScape: A web service based application for exploring and disseminating US conterminous geospatial cropland data products for decision support. Comput. Electron. Agric., 84, 111-123, https://doi.org/10.1016/j .compag.2012.03.005.

Hodshire, A. L., and Coauthors, 2016: Multiple newparticle growth pathways observed at the US DOE Southern Great Plains field site. Atmos. Chem. Phys., 16, 9321-9348, https://doi.org/10.5194/acp-16-9321 -2016 .

Homer, C. G., and Coauthors, 2015: Completion of the 2011 National Land Cover Database for the conterminous United States-Representing a decade of land cover change information. Photogramm. Eng. Remote Sensing, 81, 345-354.

Janssen, R. H. H., L. N. Ganzeveld, P. Kabat, M. Kumala, T. Nieminen, and R. A. Robeling, 2011: Estimating seasonal variations in cloud droplet number concentration over the boreal forest from satellite observations. Atmos. Chem. Phys., 11, 7701-7713, https://doi .org/10.5194/acp-11-7701-2011.

Jensen, M. P., and Coauthors, 2015: The Midlatitude Continental Convective Clouds Experiment (MC3E) sounding network: Operations, processing and analysis. Atmos. Meas. Tech., 8, 421-434, https://doi .org/10.5194/amt-8-421-2015.

Khairoutdinov, M. F., and D. A. Randall, 2003: Cloud resolving modeling of the ARM summer 1997 IOP: Model formulation, results, uncertainties, and sensitivities. J. Atmos. Sci., 60, 607-625, https://doi .org/10.1175/1520-0469(2003)060<0607:CRMOTA $>2.0 . \mathrm{CO} ; 2$.

Koster, R. D., and Coauthors, 2004: Regions of strong coupling between soil moisture and precipitation. Science, 305, 1138-1140, https://doi.org/10.1126 /science.1100217.

— , and Coauthors, 2006: GLACE: The Global LandAtmosphere Coupling Experiment. Part I: Overview. J. Hydrometeor., 7, 590-610, https://doi.org/10.1175 /JHM510.1.

Kuang, C., P. H. McMurry, and A. V. McCormick, 2009: Determination of cloud condensation nuclei production from measured new particle formation events. Geophys. Res. Lett., 36, L09822, https:/doi .org/10.1029/2009GL037584.

Kulmala, M., A. Laaksonen, and L. Pirjolam, 1998: Parameterizations for sulfuric acid/water nucleation rates. J. Geophys. Res., 103, 8301-8307, https://doi .org/10.1029/97JD03718. 
—, H. Vehkamäki, T. Petäjä, M. Dal Maso, A. Lauri, V.-M. Kerminen, W. Birmili, and P. H. McMurry, 2004: Formation and growth rates of ultrafine atmospheric particles: A review of observations. $J$. Aerosol Sci., 35, 143-176, https://doi.org/10.1016/j .jaerosci.2003.10.003.

Lee, B. H., and Coauthors, 2016: Highly functionalized organic nitrates in the southeast United States: Contribution to secondary organic aerosol and reactive nitrogen budgets. Proc. Natl. Acad. Sci. USA, 113, 1516-1521, https://doi.org/10.1073/pnas .1508108113 .

Lee, Y. N., and J. A. Lind, 1986: Kinetics of aqueousphase oxidation of nitrogen(III) by hydrogen peroxide. J. Geophys. Res., 91, 2793-2800, https://doi .org/10.1029/JD091iD02p02793.

Long, C. N., A. Bucholtz, H. Jonsson, B. Schmid, A. Vogelmann, and J. Wood, 2010: A method of correcting for tilt from horizontal in downwelling SW measurements on moving platforms. Open Atmos. Sci., 4, 78-87, https://doi.org/10.2174/18742823010 04010078 .

Lu, M.-L., G. Feingold, H. H. Jonsson, P. Y. Chuang, H. Gates, R. C. Flagan, and J. H. Seinfeld, 2008: Aerosol-cloud relationships in continental shallow clouds. J. Geophys. Res., 113, D15201, https://doi .org/10.1029/2007JD009354.

McNeill, V. F., 2015: Aqueous organic chemistry in the atmosphere: Sources and chemical processing of organic aerosols. Environ. Sci. Technol., 49, 1237-1244, https://doi.org/10.1021/es5043707.

McPherson, R. A., and Coauthors, 2007: Statewide monitoring of the mesoscale environment: A technical update on the Oklahoma Mesonet. $J$. Atmos. Oceanic Technol., 24, 301-321, https://doi .org/10.1175/JTECH1976.1.

Morcrette, C. J., and Coauthors, 2018: Introduction to CAUSES: Description of weather and climate models and their near-surface temperature errors in 5 day hindcasts near the southern Great Plains J. Geophys. Res. Atmos., 123, 2655-2683, https://doi .org/10.1002/2017JD027199.

Morrison, H., G. Thompson, and V. Tatarskii, 2009: Impact of cloud microphysics on the development of trailing stratiform precipitation in a simulated squall line: Comparison of one- and two-moment schemes. Mon. Wea. Rev., 137, 991-1007, https://doi .org/10.1175/2008MWR2556.1.

Noone, K. B., K. J. Noone, and J. A. Ogren, 1993: In situ observations of cloud microphysical properties using the counterflow virtual impactor. J. Atmos. Oceanic Technol., 10, 294-303, https://doi.org/10.1175/1520 -0426(1993)010<0294:ISOOCC >2.0.CO;2.
Ogren, J. A., J. Heintzenberg, A. Zuber, K. J. Noone, and R. J. Charlson, 1989: Measurements of the size-dependence of solute concentrations in cloud droplets. Tellus, 41B, 24-31, https://doi.org/10.3402 /tellusb.v41i1.15044.

Parworth, C., J. D. Fast, F. Mei, T. Shippert, C. Sivaraman, A. Tilp, T. Watson, and Q. Zhang, 2015: Long-term measurements of submicrometer aerosol chemistry at the ARM Southern Great Plains (SGP) site using an Aerosol Chemical Speciation Monitor (ACSM). Atmos. Environ., 106, 43-55, https://doi .org/10.1016/j.atmosenv.2015.01.060.

Paulot, F., J. D. Crounse, H. G. Kjaergaard, A. Kürten, J. M. St. Clair, J. H. Seinfeld, and P. O. Wennberg, 2009: Unexpected epoxide formation in the gas-phase photooxidation of isoprene. Science, 325, 730-733, https://doi.org/10.1126/science.1172910.

Petters, M. D., and S. M. Kreidenweis, 2007: A single parameter representation of hygroscopic growth and cloud condensation nucleus activity. Atmos. Chem. Phys., 7, 1961-1971, https://doi.org/10.5194 /acp-7-1961-2007.

Phillips, T. J., and Coauthors, 2017: Using ARM observations to evaluate climate model simulations of landatmosphere coupling on the U.S. Southern Great Plains. J. Geophys. Res. Atmos., 122, 11 524-11 548, https://doi.org/10.1002/2017JD027141.

Pierce, J. R., and P. J. Adams, 2009: Uncertainty in global CCN concentrations from uncertain aerosol nucleation and primary emission rates. Atmos. Chem. Phys., 9, 1339-1356, https://doi.org/10.5194 /acp-9-1339-2009.

Randall, D., 2013: Beyond deadlock. Geophys. Res. Lett., 40, 5970-5976, https://doi.org/10.1002/2013GL057998.

Riccobono, F., and Coauthors, 2014: Oxidation products of biogenic emissions contribute to nucleation of atmospheric particles. Science, 344, 717-721, https:// doi.org/10.1126/science.1243527.

Rieck, M., C. Hohenegger, and C. C. van Heerwaarden, 2014: The influence of land surface heterogeneities on cloud size development. Mon. Wea. Rev., 142, 3830-3846, https://doi.org/10.1175/MWR-D-13 -00354.1 .

Schmid, B., and Coauthors, 2014: The DOE ARM Aerial Facility. Bull. Amer. Meteor. Soc., 95, 723-742, https:// doi.org/10.1175/BAMS-D-13-00040.1.

Seigneur, C., and P. Saxena, 1988: A theoretical investigation of sulfate formation in clouds. Atmos. Environ., 22, 101-115, https://doi.org/10.1016/0004 -6981(88)90303-4.

Shaw, R. A., W. C. Reade, L. R. Collins, and J. Verlinde, 1998: Preferential concentration of cloud droplets by turbulence: Effects on the early evolution of cumulus 
cloud droplet spectra. J. Atmos. Sci., 55, 1965-1976, https://doi.org/10.1175/1520-0469(1998)055<1965: PCOCDB $>2.0 . C O ; 2$.

Shilling, J. E., and Coauthors, 2013: Enhanced SOA formation from mixed anthropogenic and biogenic emissions during the CARES campaign. Atmos. Chem. Phys., 13, 2091-2113, https://doi.org/10.5194 /acp-13-2091-2013.

Shrivastava, M., and Coauthors, 2013: Modeling aerosols and their interaction with shallow cumuli during the 2007 CHAPS field study. J. Geophys. Res. Atmos., 118, 1343-1360, https://doi.org/10.1029/2012JD018218.

Sisterson, D. L., R. A. Peppler, T. S. Cress, P. J. Lamb, and D. D. Turner, 2016: The ARM Southern Great Plains (SGP) site. The Atmospheric Radiation Measurement (ARM) Program: The First 20 Years, Meteor. Monogr., No. 57, Amer. Meteor. Soc., https://doi.org/10.1175 /AMSMONOGRAPHS-D-16-0004.1.

Skamarock, W. C., and Coauthors, 2008: A description of the Advanced Research WRF version 3. NCAR Tech. Note NCAR/TN-475+STR, 113 pp., https:// doi.org/10.5065/D68S4MVH.

Tucker, S. C., C. J. Senff, A. M. Weickmann, W. A. Brewer, R. M. Banta, S. P. Sandberg, D. C. Law, and R. M. Hardesty, 2009: Doppler lidar estimation of mixing height using turbulence, shear, and aerosol profiles. J. Atmos. Oceanic Technol., 26, 673-688, https://doi.org/10.1175/2008JTECHA1157.1.

Tuttle, S., and G. Salvucci, 2016: Empirical evidence of contrasting soil moisture-precipitation feedbacks across the United States. Science, 352, 825-828, https://doi.org/10.1126/science.aaa7185.

Twohy, C. H., M. D. Petters, J. R. Snider, B. Stevens, W. Tahnk, M. Wetzel, L. Russell, and R. Burnet, 2005: Evaluation of the aerosol indirect effect in marine stratocumulus clouds: Droplet number, size, liquid water path, and radiative impact. $J$. Geophys. Res., 110, D08203, https://doi.org/10.1029 /2004JD005116.

Twomey, S., 1977: The influence of pollution on the shortwave albedo of clouds. J. Atmos. Sci., 34,
1149-1152, https://doi.org/10.1175/1520-0469(1977) 034<1149:TIOPOT>2.0.CO;2.

Vogelmann, A.M., and Coauthors, 2012: RACORO extended-term aircraft observations of boundary layer clouds. Bull. Amer. Meteor. Soc., 93, 861-878, https://doi.org/10.1175/BAMS-D-11-00189.1.

Wang, J., M. Pikridas, S. R. Spielman, and T. Pinterich, 2017: A fast integrated mobility spectrometer for rapid measurement of sub-micrometer aerosol size distribution, Part I: Design and model evaluation. J. Aerosol Sci., 108, 44-55, https://doi.org/10.1016/j .jaerosci.2017.02.012.

Weckwerth, T. M., and Coauthors, 2004: An overview of the International $\mathrm{H}_{2} \mathrm{O}$ Project (IHOP_2002) and some preliminary highlights. Bull. Amer. Meteor. Soc., 85, 253-277, https://doi.org/10.1175/BAMS-85-2-253. Wood, R., 2012: Stratocumulus clouds. Mon. Wea. Rev., 140, 2373-2423, https://doi.org/10.1175/MWR -D-11-00121.1.

Xiao, H., L. K. Berg, and M. Huang, 2018: The impact of surface heterogeneities and land-atmosphere interactions on shallow clouds over ARM SGP site. J. Adv. Model. Earth Syst., 10, 1220-1244, https://doi .org/10.1029/2018MS001286.

Zelenyuk, A., and Coauthors, 2010: In situ characterization of cloud condensation nuclei, interstitial, and background particles using the Single Particle Mass Spectrometer, SPLAT II. Anal. Chem., 82, 7943-7951, https://doi.org/10.1021/ac1013892.

__ _ _ J. Wilson, Z. Zhang, J. Wang, and K. Mueller, 2015: Airborne single particle mass spectrometers (SPLAT II \& miniSPLAT) and new software for data visualization and analysis in a geo-spatial context. $J$. Amer. Soc. Mass Spectrom., 26, 257-270, https://doi .org/10.1007/s13361-014-1043-4.

Zhang, Y., and S. A. Klein, 2013: Factors controlling the vertical extent of fair-weather shallow cumulus clouds over land: Investigation of diurnal-cycle observations collected at the ARM Southern Great Plains site. J. Atmos. Sci., 70, 1297-1315, https://doi .org/10.1175/JAS-D-12-0131.1. 